\title{
Development of Electromagnetic Band Gap Structures in the Perspective of Microstrip Antenna Design
}

\author{
Md. Shahidul Alam, ${ }^{1,2}$ Norbahiah Misran, ${ }^{1}$ \\ Baharudin Yatim, ${ }^{2}$ and Mohammad Tariqul Islam \\ ${ }^{1}$ Department of Electrical, Electronic and Systems Engineering, Faculty of Engineering and Built Environment, \\ Universiti Kebangsaan Malaysia (UKM), 43600 Bangi, Selangor, Malaysia \\ ${ }^{2}$ Institute of Space Science (ANGKASA), Universiti Kebangsaan Malaysia (UKM), 43600 Bangi, Selangor, Malaysia
}

Correspondence should be addressed to Md. Shahidul Alam; titu_jfc@yahoo.com

Received 18 February 2013; Accepted 25 March 2013

Academic Editor: Mandeep Singh Jit Singh

Copyright (C) $2013 \mathrm{Md}$. Shahidul Alam et al. This is an open access article distributed under the Creative Commons Attribution License, which permits unrestricted use, distribution, and reproduction in any medium, provided the original work is properly cited.

Electromagnetic band gap (EBG) technology has become a significant breakthrough in the radio frequency (RF) and microwave applications due to their unique band gap characteristics at certain frequency ranges. Since 1999, the EBG structures have been investigated for improving performances of numerous $\mathrm{RF}$ and microwave devices utilizing the surface wave suppression and the artificial magnetic conductor (AMC) properties of these special type metamaterial. Issues such as compactness, wide bandwidth with low attenuation level, tunability, and suitability with planar circuitry all play an important role in the design of EBG structures. Remarkable efforts have been undertaken for the development of EBG structures to be compatible with a wide range of wireless communication systems. This paper provides a comprehensive review on various EBG structures such as three-, two-, and onedimensional (3D, 2D, and 1D) EBG, mushroom and uniplanar EBG, and their successive advancement. Considering the related fabrication complexities, implementation of vialess EBG is an attractive topic for microwave engineers. For microstrip antennas, EBG structures are used in diversified ways, which of course found to be effective except in some cases. The EBG structures are also successfully utilized in antenna arrays for reducing the mutual coupling between elements of the array. Current challenges and limitations of the typical microstrip antennas and different EBG structures are discussed in details with some possible suggestions. Hopefully, this survey will guide to increasing efforts towards the development of more compact, wideband, and high-efficient uniplanar EBG structures for performance enhancement of antenna and other microwave devices.

\section{Introduction}

Recent advances in wireless communication systems demand more advanced or special type of electromagnetic materials for high-performance applications, and it opened up new dimensions in the electromagnetic field. The inception and development of the "metamaterial" concept over the year introduced a revolution and got a great attention from the researchers [1]. Metamaterials cover an extremely large scientific domain which ranges from optics to nanoscience and from material science to antenna engineering [2-5]. These composite materials show unique features which cannot be found in nature. Broadly, these can be defined as "artificial effectively homogeneous electromagnetic structures with unusual properties not readily available in nature" [6]. Another definition is as "artificially structured materials that are designed to interact with and control electromagnetic waves" [7]. Depending on the exhibited electromagnetic properties, artificially structured materials have a variety of names in the literature [4], including: double negative (DNG) materials, left-handed (LH) materials, negative refractive index (NRI) materials, magneto materials, soft and hard surfaces, high-impedance surfaces, and artificial magnetic conductors (AMC).

A simple synopsis of these metamaterials is shown in Figure 1, where the angular frequencies $\omega_{\mathrm{pe}}$ and $\omega_{\mathrm{pm}}$ represent the electric and magnetic plasma frequency, respectively [8]. It is worthwhile to point out that some of these interesting 


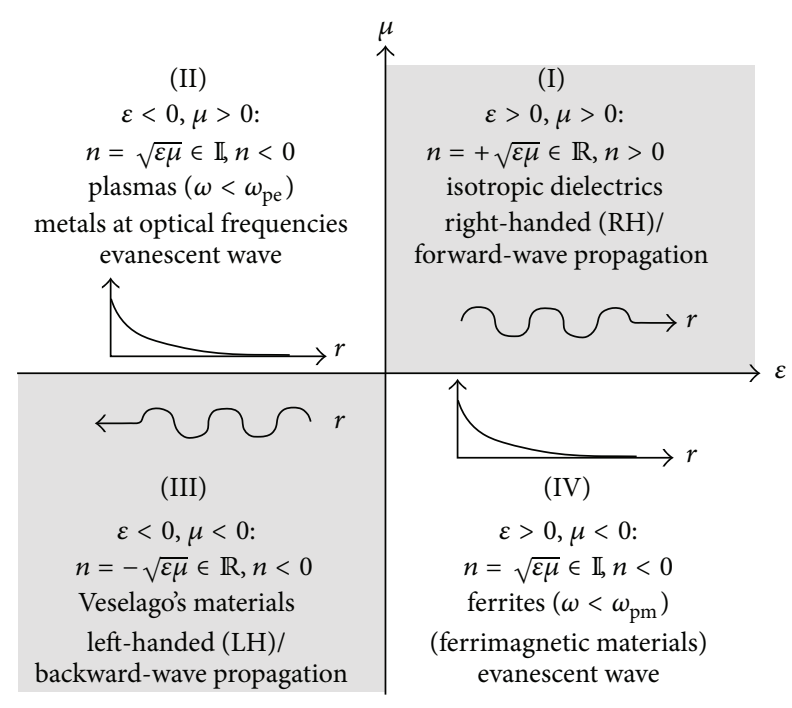

FIGURE 1: Permittivity, permeability, and refractive index diagram.

electromagnetic characteristics are related to each other. For example, the DNG materials always exhibit both the left-handed property and the negative refractive index. A periodic composite transmission line structure may exhibit the left-handed property in one frequency region and band gap property in another frequency region [4]. Thus, it is an exciting area for researchers to explore these unique properties and their relations for different metamaterials and apply them in various electromagnetics and antenna applications. Due to their unique band gap features, EBG structures can be regarded as a special type of metamaterials $[4,5,9]$. When they interact with electromagnetic waves, exciting phenomena appear and amazing features result. In particular, characteristics such as frequency stop bands, passbands, and band gaps could be identified.

The concept of electromagnetic band-gap (EBG) structures originates from the solid-state physics and optic domain, where photonic crystals with forbidden band-gap for light emissions were proposed in 1987 [10, 11]. Thus, the terminology photonic band gap (PBG) of the optics is popularly used as EBG in microwave domain. Since then, a profusion of scientific creativity has been witnessed, as new forms of electromagnetic structures are invented for radio frequency and microwaves [4]. Figure 2 shows some examples of the PBG structures.

EBGs are periodic arrangements of dielectric or metallic elements in one-, two-, or three- dimensional manner. A periodic structure can give rise to multiple band gaps since the band gap is not only due to the periodicity of the structure but also due to the individual resonance of one element. The band gap formation in EBG is due to the interplay between macroscopic and microscopic resonances of a periodic structure $[12,13]$. The periodicity governs the macroscopic resonance or the Bragg resonance, the lattice resonance, whereas the microscopic resonance is due to the element characteristics, and it is called the Mie resonance [8]. When the two resonances coincide, the structure possesses a band gap having maximum width. Depending on the structural characteristics and polarization of the wave, one of the stop band resonance mechanism can dominate over the other [4]. At the stop band, the structure will reflect back all electromagnetic waves, whilst at other frequencies it will act as a transparent medium.

Reviewing the literature, it was observed that various terminologies have been used depending on the domain of the applications. These applications are seen in filter designs, gratings, frequency selective surfaces (FSS) [14], photonic crystals [15] and photonic band gaps (PBG) [11], and so forth. In 2003, Samii and Mossalaei classified them under the broad terminology of "Electromagnetic Band Gap (EBG)" structures, and the EBG structures are defined as [4] "artificial periodic (or sometimes nonperiodic) objects that prevent/assist the propagation of electromagnetic waves in a specified band of frequency for all incident angles and all polarization states".

Besides the band gap feature, EBG also possesses some other exciting properties, such as high impedance and AMC. For example, a mushroom-like EBG surface exhibits high surface impedances for both TE and TM polarizations. When a plane wave illuminates the EBG surface, an in-phase reflection coefficient is obtained resembling an artificial magnetic conductor. In addition, soft and hard operations of an EBG surface have also been identified in the frequencywave number plane [4]. These interesting features have led to a wide range of applications in antenna engineering, from wire antennas to microstrip antennas, from linearly polarized antennas to circularly polarized antennas, and from the conventional antenna structures to novel surface wave antenna concepts and reconfigurable antenna designs.

This paper gives a comprehensive review on the recent advancement of EBG structures and their versatile applications specially in enhancing microstrip antenna performances. Several techniques to widen the band gap of an EBG structure and mutual coupling reduction ability of them are also discussed. This literature survey will hopefully set a starting point for other researchers about the present stateof-the-art of EBG research and will be helpful for microstrip antenna designs.

\section{Applications of the EBG Structures}

EBG structures received great attention due to their interesting properties, and their applications are spreading as fast as the advancement of the wireless communication systems and the fabrication technology. A multitude of basic EBG applications exists especially within the microwave and low millimeter-wave region, for example, in electronically scanned phased arrays, high-precision GPS, Bluetooth, mobile telephony, waveguides, antennas, low loss-coplanar lines, and compact integrated filters [16-21]. In the microwave domain, many developments concern the direct control of the electromagnetic energy and its transmission: mirrors, electromagnetic windows, and radiation pattern control. Other applications include duplexers and controllable PBG materials. 

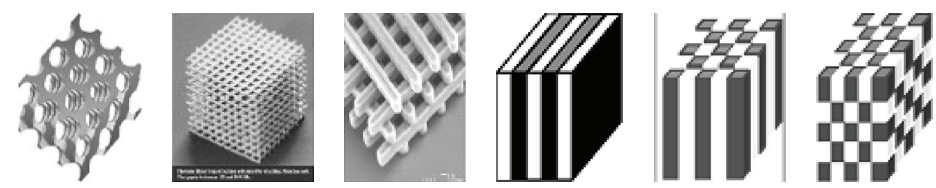

FIgURe 2: Typical examples of PBG structures.

EBG structures are used to prevent some undesired operating modes and control harmonics, also as a band reject especially for ultrawideband (UWB) applications where several other applications coexist. More attention is being paid to the shielding property of the EBG to reduce specific absorption rate or SAR (back radiation) into mobile phone operator's hand and head [22-24]. Also, it can shield the antennas from unwanted multipath signals which is important in multipoint communications [16]. In microwave filtering, the broad stopband can be exploited to suppress spurious passbands [25]. In addition to these, a standard waveguide can be modified by placing of electromagnetic crystal on the two sidewalls of a waveguide [26], potentially creating a very efficient waveguiding structure.

\section{Methods for Identification of the EBG Properties}

The electromagnetic band gap (EBG) of a structure can be determined from the reflection phase, the dispersion diagram, and the transmission characteristics calculated by the suspended microstrip line method or the directive transmission method.

The electromagnetic nature of a surface is predictable from the reflection phase characteristics, such that a $180^{\circ}$ reflection phase implies a perfect electric conductor (PEC) surface and a $0^{\circ}$ reflection phase resembles a perfect magnetic conductor (PMC) surface. If a plane wave is normally impinged upon a PEC, the total tangential $E$ field must be zero in order to satisfy the boundary condition. Thus, the reflected $E$ field and the incident $E$ field should have the opposite signs, resulting in a reflection coefficient of -1 . The reflection phase is $180^{\circ}$ for the PEC case. Similarly, for a PMC, the reflected $H$ field and the incident $H$ field should have the opposite signs whereas the reflected $E$ field and the incident $E$ field have the same signs. As a result, the reflection coefficient is equal to +1 , and the corresponding reflection phase is $0^{\circ}$ for PMC case [4]. However, the PMC surface does not exist in nature. The reflection phase of an EBG surface varies from $+180^{\circ}$ to $-180^{\circ}$ with increasing frequency [27], and the frequency region between $+90^{\circ}$ and $-90^{\circ}$ usually coincides with the band gap of the EBG. Figure 3(a) shows a typical reflection phase diagram.

Often the band gap of a periodic structure is calculated from its dispersion characteristics [28], which can be obtained by an eigenmode solver. The eigenmode solver determines the resonant frequency for a given wavenumber which is an important parameter to describe the propagation property of electromagnetic waves. There may exist several different propagation constants at the same frequency. Each one is known as a specific mode with its own phase velocity, group velocity, and field distribution. The relation between phase constant and resonant frequency is often plotted out and referred to as the dispersion diagram $[4,5]$. As shown in Figure 3(b), the gray area is the resulted band gap for a structure.

The transmission characteristic of an EBG structure is obtainable through the suspended microstrip line and the directive transmission (waveguide simulation) methods. In the suspended line method, the band gap is characterized by using the EBG array as a ground plane for a microstrip transmission line, which is suspended above the array [2931]. This method is much similar to the implementation of an EBG as a filter. It is very simple, time saving and used to find the surface wave suppression characteristics of EBG structures. As depicted in Figure 3(c), the frequency range with attenuation losses of less than $-10 \mathrm{~dB}$ or $-20 \mathrm{~dB}$ is usually considered as the band gap [29]. The other one, directive transmission method, consider a finite number of unit cell into a two port TEM waveguide with periodicity along the main direction of propagation, and transmission result is calculated [32].

Regarding the EBG design especially for antenna applications, the reflection phase and the transmission responses are sufficient for investigating the band gap characteristics. From the reflection phase diagram, the AMC point $\left(0^{\circ}, \mathrm{PMC}\right.$ property), and from the transmission responses the surface wave band gap of the EBG structure can be easily identified. In contrast, the dispersion diagram would give more information of band gap, but it requires much higher time and memory allocation. The time and memory allocation requirements increase with the structural complexity.

\section{Development of Various EBG Configurations}

EBG structures can be broadly categorized into three groups according to their geometric configuration: (1) threedimensional volumetric structures, (2) two-dimensional planar surfaces, and (3) one-dimensional transmission lines [4]. The dimensionality depends on the periodicity directions. The first attempts towards three-dimensional structures were realized in the form of face centered cubic (FCC) lattice structures [33]. At the initial stages of EBG research, due to the lack of theoretical predictions, a "cut and try" approach was adopted in experimentally predicting the band gap. Figure 4(a) shows a representative 3-D EBG structure $[34,35]$.

In the late 1990s, two important planar EBG structures were invented, where metallic components were effectively incorporated into the unit cells. One is the mushroom-like EBG surface $[10,18,27,32,36]$ and the other is the uniplanar 

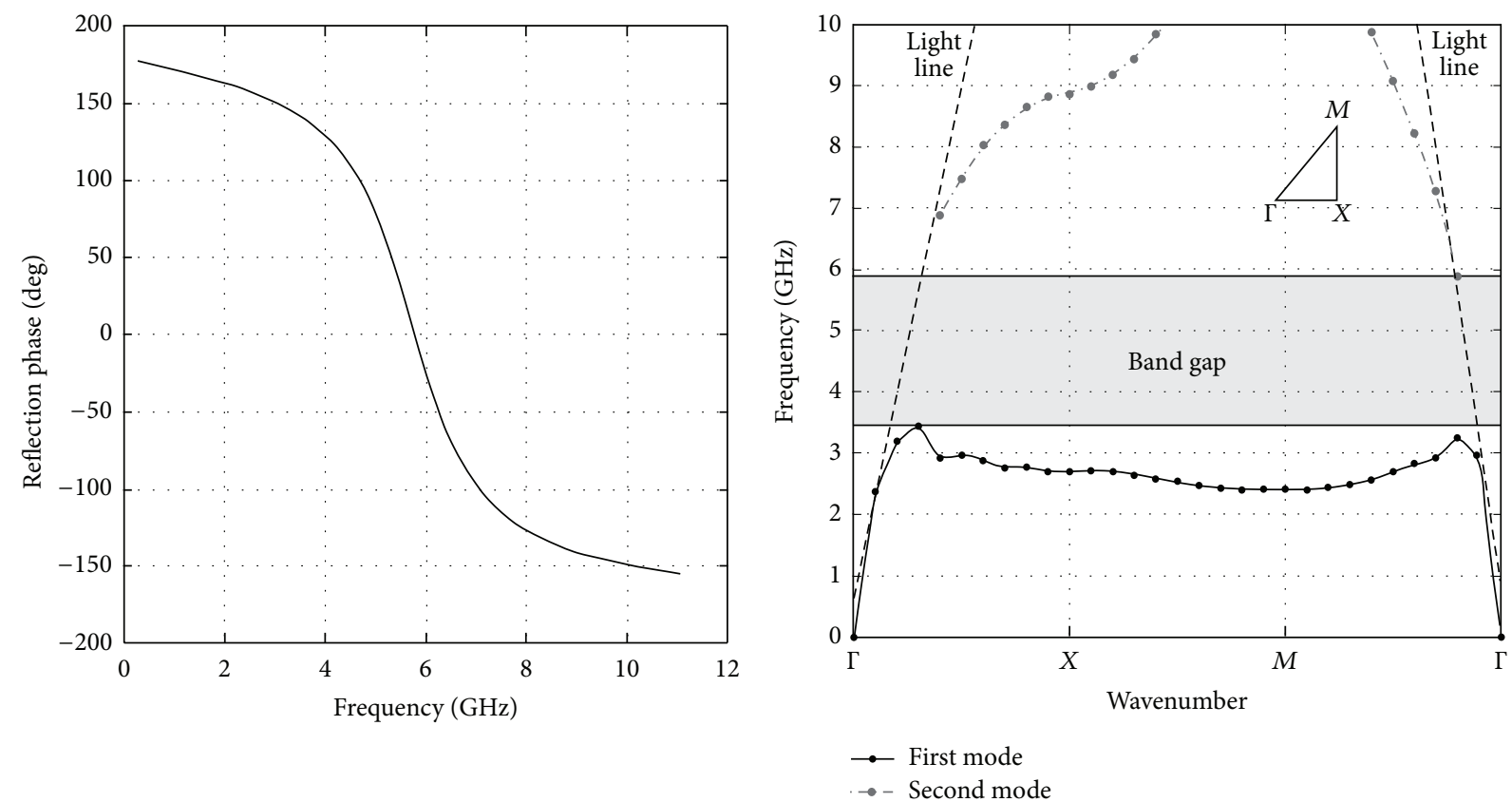

(a)

(b)

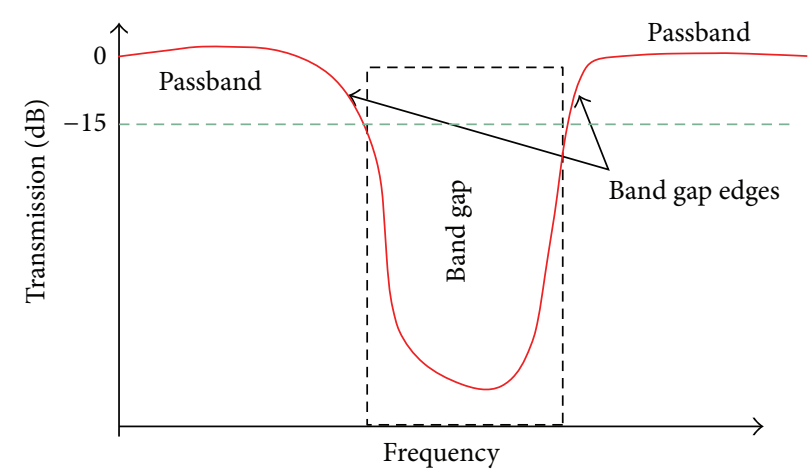

(c)

Figure 3: Identification of bandgap of a EBG surface (a) reflection phase (b), dispersion diagram, and (c) transmission loss plot.

EBG surface $[14,17,19,26,27,29,30,37-39]$ which are as shown in Figure 4(b). The mushroom-like EBG exhibits band gap at lower frequencies compared to uniplanar EBG, but it is associated with fabrication complexities due to the vertical via placement and requires thick dielectric material. On the other side, uniplanar EBG has no vertical vias and is suitable for thin substrate material which makes the fabrication easier [13, 38]. In addition, it is less sensitive to the incident angle and polarization [4]. An example of 1-D EBG transmission line design is plotted in Figure 4(c). The planar electromagnetic band gap (EBG) surfaces exhibit distinctive electromagnetic properties with respect to incident electromagnetic waves [5]:

(i) when the incident wave is a plane wave, the reflection phase of the EBG structures varies with frequency. At a certain frequency the reflection phase is zero degrees, which resembles a perfect magnetic conductor that does not exist in nature; (ii) when the incident wave is a surface wave, the EBG structures show a frequency band gap through which the surface wave cannot propagate for any incident angles and polarization states.

Both theoretical and experimental advancement has driven the rapid development of EBG technology, with emphasis grown on designing compact and uniplanar shaped EBG structures. Unlike the mushroom EBG, uniplanar EBGs are constructed by interconnecting unit cells on the top layer to realize a high-impedance surface with good stop band characteristics at the desired frequency range. The surface impedance is frequency sensitive since the EBG surface forms a distributed $L C$ network with a specific frequency band. The electromagnetic properties can be illustrated using lump-circuit elements-inductors $(L)$ and capacitors $(C)$. At the stopband frequency range, the equivalent $L C$ network behaves as a two-dimensional electric filter to restrict the propagation of surface waves $[26,27,38]$. The inductor $L$ 


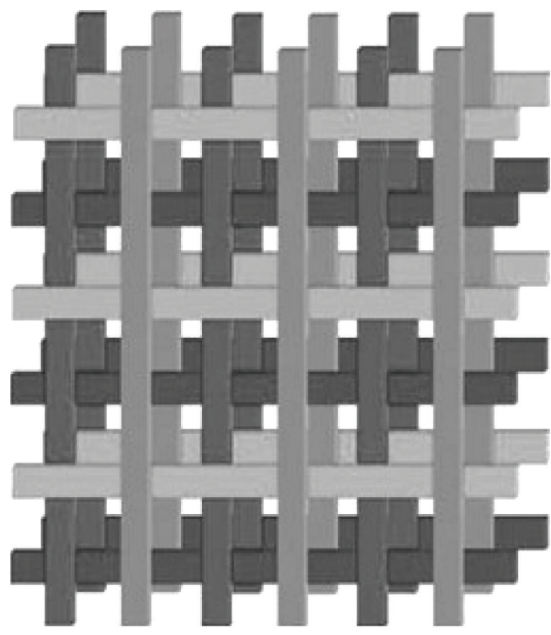

(a)

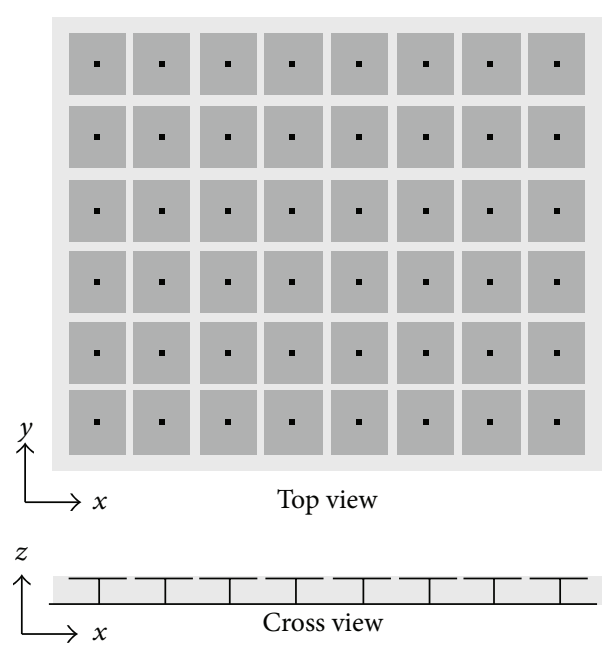

(b)

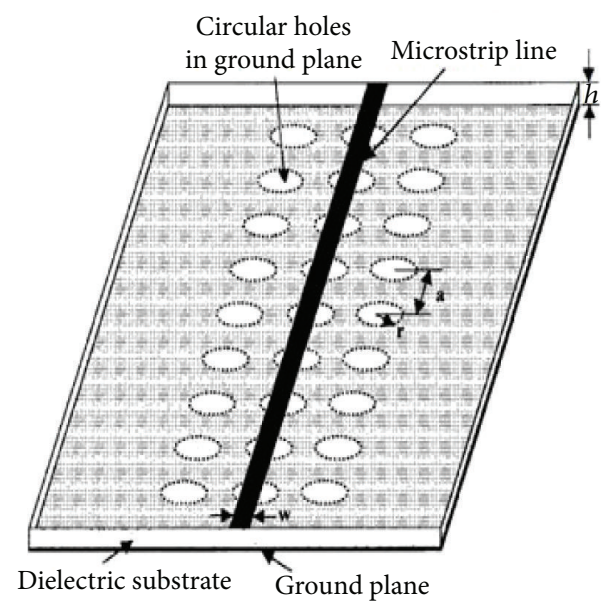

(c)

FIGURE 4: EBG structures: (a) 3-D EBG: a woodpile dielectric structure, (b) 2-D EBG: a mushroom EBG, and (c) 1-D EBG: a microstrip line with periodic holes on the ground plane.

results from the thin connecting lines while the capacitor $C$ due to the gaps within a cell and gaps between adjacent cells. Based on this concept, diverse forms of UC-EBG structures have been proposed, since the idea was first introduced by Yang et al. in 1999. These structures are studied extensively and applied to design nonleaky coplanar waveguide, microstrip bandpass filter [26], and aperture-coupled microstrip antenna [40]. Intending to obtain wideband UCEBG, various topologies have been used such as meandered line and spiral shapes.

In 2005, Folayan and Langley [41] proposed a uniplanar design for lower band applications around $2.4 \mathrm{GHz}$, which consists of two different bow-tie geometry as shown in Figure 5. The outer hollow bow-tie arm's length and unit cell spacing control the first band gap, while the second band gap is controlled by the inner bow-tie arm's length $(w)$ and gap width $(g)$. A unit cell size is $22.3 \times 22.3 \mathrm{~mm}^{2}$, with $w=12.2 \mathrm{~mm}, g=2.3 \mathrm{~mm}$, and the element spacing of the fabricated $8 \times 8$ array is $0.5 \mathrm{~mm}$. The reflection phase bands are $11.4 \%$ at $1.55 \mathrm{GHz}$ and $6 \% 2.5 \mathrm{GHz}$, while the transmission responses exhibit a band gap of $24 \%$ at $1.6 \mathrm{GHz}$. A $3.5 \mathrm{~mm}$ thick substrate with dielectric constant of 4.4 is used in this design.

In the next year, Toyota et al. [42] performed studies regarding the size reduction of vialess planar EBG structure with new geometries and high permittivity materials. To meet demand for compact wireless devices and reduce EM interference or digital noise in RF/analog circuits operating in the lower bands, it is desired to achieve stop band with smaller patch size. Two important approaches are proposed to lower the stop band and reduce the overall size: (a) introduction of narrow slits into the patch in geometry and (b) application of high permittivity material. The narrow slits increase inductances, whereas high dielectric material increases capacitances. The on-set frequency of the stop band is shifted from 4.8 to $1.8 \mathrm{GHz}$, while up to $40 \%$ size reduction is achieved by substituting the $0.127 \mathrm{~mm}$ thick FR4 $\left(\varepsilon_{r}=4.0\right)$ with a high permittivity $\left(\varepsilon_{r}=30\right)$ substrate. The optimized 


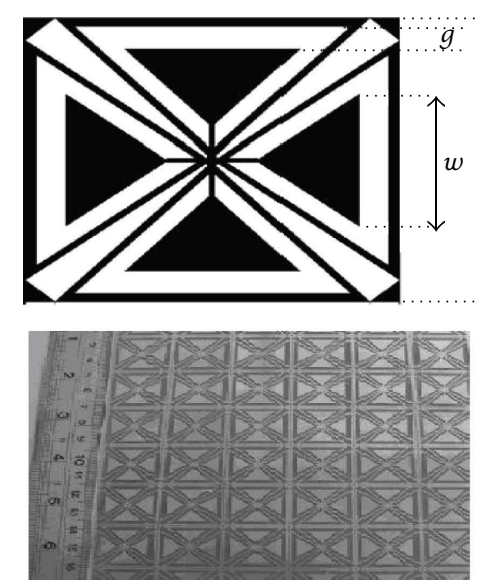

(a)

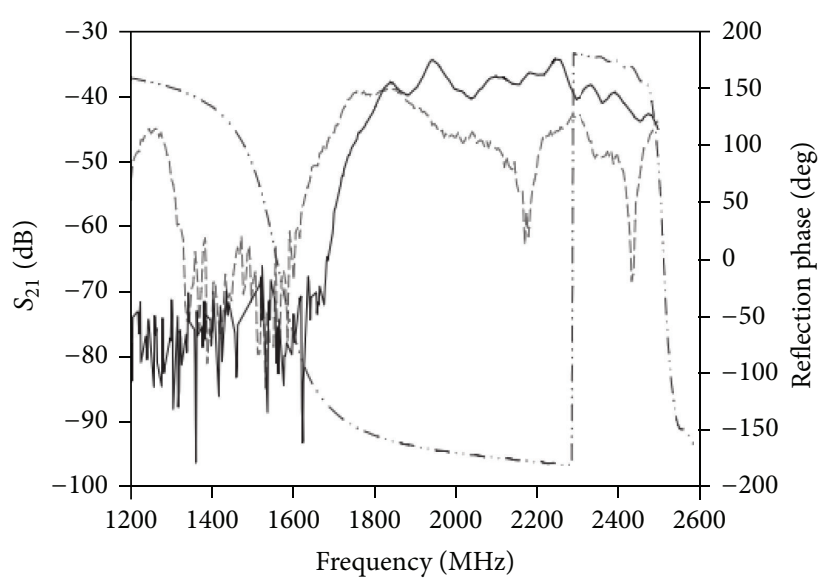

(b)

FIGURE 5: Wideband EBG: (a) single EBG element and an array (periodicity $22.8 \mathrm{~mm}$ ). (b) Simulated reflection phase and measured transmission responses, [- - - TM mode, -TE mode, -.--, and reflection phase].

EBG cell size is $18.8 \times 18.8 \mathrm{~mm}^{2}$ with $0.2 \mathrm{~mm}$ slit width. The EBG design and comparative studies are presented in Figure 6. Though wide stop band at lower band is achieved, there are issues like manufacturing tolerances and material expenses that are needed to be considered.

Figure 7 presents a distorted UCEBG (DUC-EBG) proposed by Lin et al. [43], which achieved a stop band of $0.7 \mathrm{GHz}$ with spans from 4.2 to $4.9 \mathrm{GHz}$. In this design, the insets of a conventional UC-EBG have been distorted and introduced into the center part of the pad. This allows to provide more inductive and capacitive effect and to achieve compactness of the EBG structure. The EBG unit cell has occupied an area of $7.2 \times 7.2 \mathrm{~mm}^{2}$ on a $1.5 \mathrm{~mm}$ thick dielectric material with permittivity of 2.65 . The DUC-EBG element parameters are chosen as $a=7.2 \mathrm{~mm}, w=0.3 \mathrm{~mm}$, $d=0.8 \mathrm{~mm}, l=3.15 \mathrm{~mm}$, and $g=0.2 \mathrm{~mm}$. The band gaps are calculated for various arrays $(1 \times 5,2 \times 5$, and $15 \times 15)$ on a grounded or bare dielectric slab. Two arrangements are considered such as (1) the DUC-EBG is mounted on a grounded dielectric slab and connected with $50-\Omega$ microstrip lines at both ends as a filter structure and (2) the DUC-EBG lattices are etched on the ground plane of a 50$\Omega$ microstrip line. The transmission characteristics for both cases are measured and shown in Figures 7(b) and 7(c), where the band gap is centered at $5 \mathrm{GHz}$, and band gap is $900 \mathrm{MHz}$ (4.1-5.0 GHz).

Waterhouse and Novak [44] introduced a small UCEBG (as shown in Figure 8) designed with very thin meandered microstrip line which is directly related to the inductances. With $25.5 \times 25.5 \mathrm{~mm}^{2}$, an array of $3 \times 3$ EBG units $(76.5 \times$ $76.5 \mathrm{~mm}^{2}$ ) was built on a $1.6 \mathrm{~mm} \mathrm{FR} 4$ dielectric material that achieved a band gap of $50 \mathrm{MHz}$ centered at $0.3 \mathrm{GHz}$. The concept of meandering microstrip line to increase the electrical length without increasing unit cell size is interesting and seen in many other designs. Then, in 2007, Liu et al. [45] presented the "ameliorated UCEBG", which is actually a modified shape of the DUC-EBG with same size and periodicity. Figure 9 shows the new pattern where the center crossing straight lines of DUC-EBG are replaced by meandered lines which act as coplanar spiral conductors. The optimized parameters are as $a=7.4 \mathrm{~mm}, w=g=0.2 \mathrm{~mm}$, and $b=6.8 \mathrm{~mm}$. Due to the inclusion of the meander lines inside, the band gap position is lowered to $3.28 \mathrm{GHz}$, though the bandwidth is same $(900 \mathrm{MHz})$.

After that, in 2008, Lin et al. [46] proposed a new design which combined the meandered line and spiral lines together and referred to as SC-ML-EBG (spiral shaped capacitor meandered line inductor EBG). It is a successive modification of a regular UC-EBG as shown in Figure 10(a). Without changing the size, spiral conductors are placed inside to increase capacitances, and meandered line inductors are placed at the edges of a unit cell. The selected design parameters for SC-ML-EBG are as $W=1.65 \mathrm{~mm}, w_{1}=0.4 \mathrm{~mm}$, and $w_{2}=g_{1}=g_{2}=0.15 \mathrm{~mm}$. A $2 \times 5$ array of $7.4 \times 7.4 \mathrm{~mm}^{2}$ unit cell is fabricated on a $1.5 \mathrm{~mm}$ substrate of permittivity 2.65 , and the measured transmission responses are plotted in Figure 10(b). Although the initial pattern shows a single band gap (at $6.5 \mathrm{GHz}$ ), the SC-ML-EBG exhibits dual band gap (at 2.5 and $5.2 \mathrm{GHz}$ ) comparatively at lower center frequency. However, the bandwidths become narrower than that of the initial pattern. At the same time, Wang et al. [47] proposed another SC-ML-EBG, which is also realized on a $1.5 \mathrm{~mm}$ thick substrate (permittivity $=2.65$ ) and has the same unit cell size. The strip widths are considered as $0.2 \mathrm{~mm}$ and the spiral and meandered lines distributed from the center pad. However, only one band gap $(0.5 \mathrm{GHz})$ is obtained at $2.6 \mathrm{GHz}$, and it is narrower than the one previously reported in [46]. Thus, it is worth to point out that proper consideration should be taken to obtain the best possible results.

Though single band EBG structures are widely studied in literature, a few multiband designs also proposed recently. In 2012, Alam et al. [38] reported a dual band split-ring slotted (SRS) EBG printed on a $1.6 \mathrm{~mm}$ FR4 substrate (permittivity 4.6), and each unit has an area of $12 \times 18 \mathrm{~mm}^{2}$. 

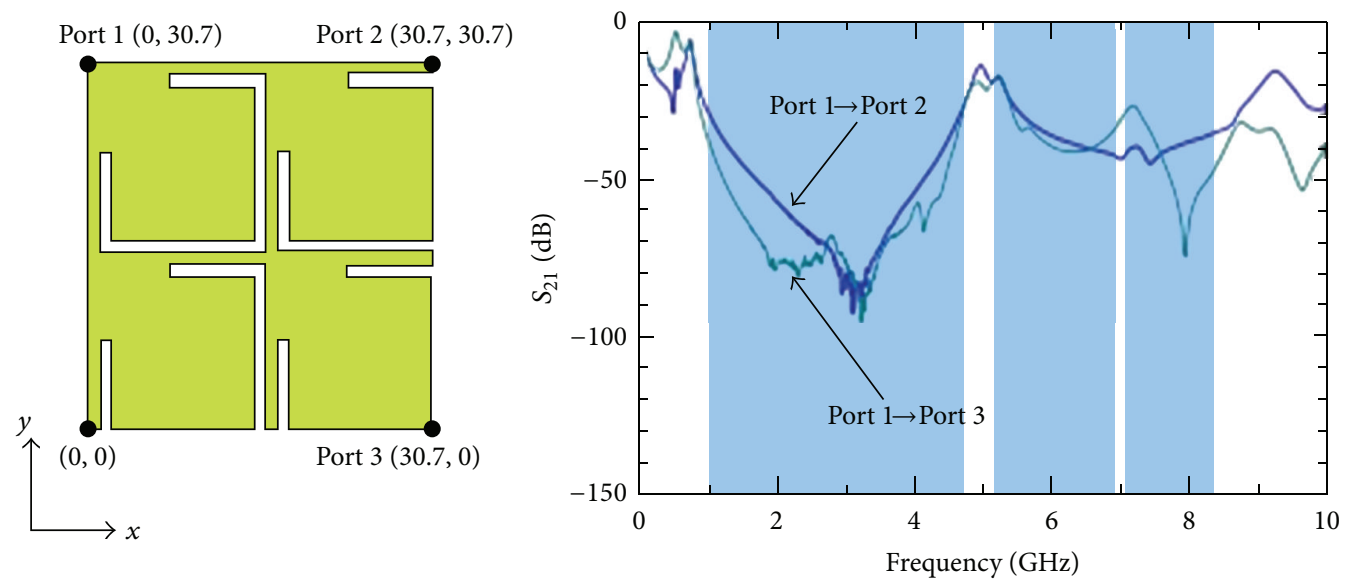

(a)
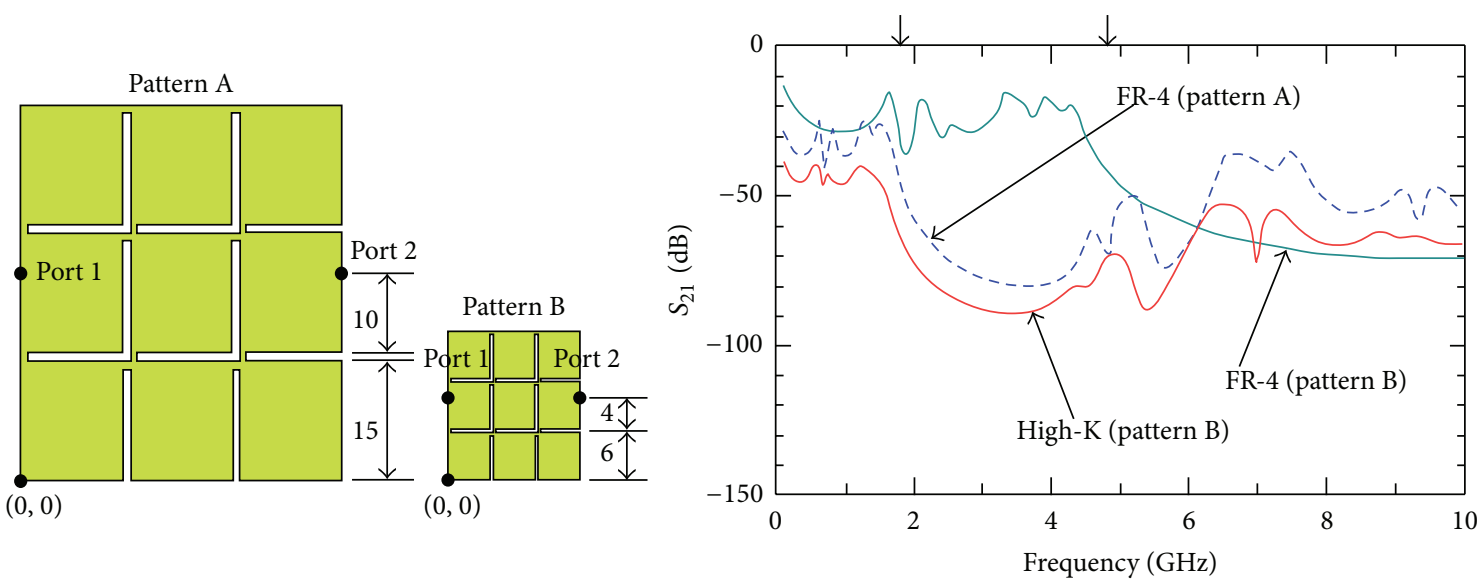

(b)

FIGURE 6: Calculated transmission coefficient $\left(S_{21}\right)$ (a) $2 \times 2$ array of EBG; (b) EBG without slits on different dielectric material.

The combinations of split-ring slots, rectangular patch, and link bridges are realized to obtain wide band gaps. Figure 11 shows the SRS-EBG geometry and its corresponding transmission responses. The measured band gaps are $3.65 \mathrm{GHz}$ $(5.2-8.85 \mathrm{GHz})$ and $4.74 \mathrm{GHz}(10.54-15.28 \mathrm{GHz})$, and the minimum $S_{21}$ value is around $-50 \mathrm{~dB}$ for the two band gaps. Most recently, a triple band EBG structure has been developed [48] with a $12 \times 12 \mathrm{~mm}^{2}$ unit cell size (periodicity $12.5 \mathrm{~mm}$ ) and built on a $1.6 \mathrm{~mm}$ FR4 substrate (permittivity 4.4). This design combined meandered line with square split ring resonators (SSRR) together to increase the inductive and capacitive effects. Selected design parameters are as $a=$ $12 \mathrm{~mm}, b=2.6 \mathrm{~mm}, c=4.3 \mathrm{~mm}, e=0.3 \mathrm{~mm}, g=0.5 \mathrm{~mm}$, $r=0.35 \mathrm{~mm}$, and $x=4.2 \mathrm{~mm}$. As shown in Figure 12, the achieved band gaps are (3.12-4.62), (4.93-5.28), and (6.007.42) $\mathrm{GHz}$.

Most of the above described structures are vialess, comparatively smaller, and designed for single band or multiband applications. The configurations are realized with very narrow strips ranging from 0.1 to $0.4 \mathrm{~mm}$, and the interelement spacing is also smaller. Though the center frequency of the band gaps are lowered by using meander lines or spiral strips, the structures are not integrated into where these are practically applicable to, such as antenna design. However, these techniques of lowering the center frequency and widening the band gap are quite interesting.

\section{EBG Structures in Microstrip Antenna Design}

In the RF and microwave research arena, microstrip antenna is a smart choice from the perspective of designing compact and cost-effective wireless communication systems [49-52]. Besides the features such as light weight, low profile, low cost, and ease of mounting on the host surface and integration with printed circuits, microstrip antennas suffer from a number of drawbacks, such as narrow bandwidth, low gain, poor radiation performance due to excitation of surface waves, and so forth [53-57]. The band gap feature of EBG structures has found useful applications in suppressing the surface waves in microstrip antenna design. These structures are also found to be effective for bandwidth improvement $[58,59]$, compact microstrip antenna designs [60], harmonic control [61], and 

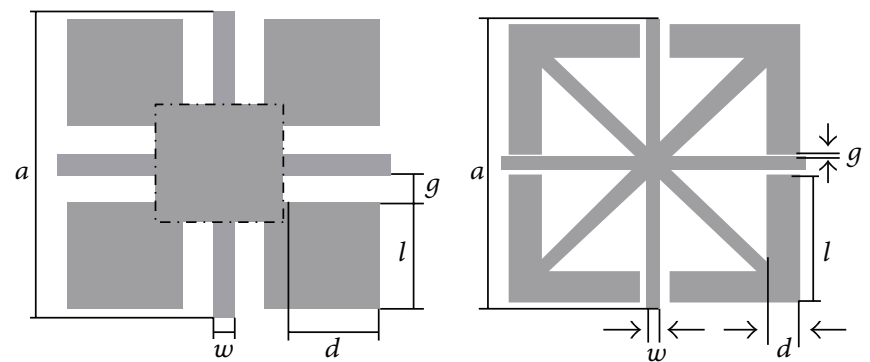

(a)

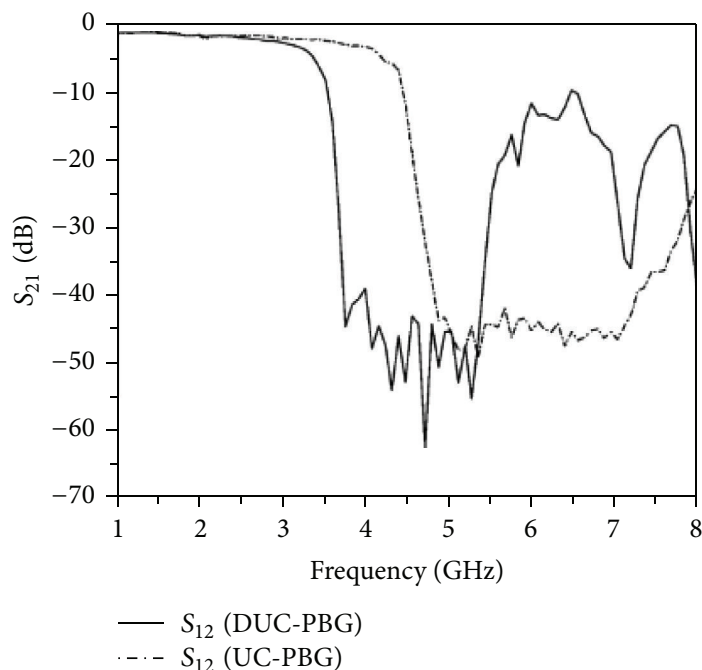

(b)

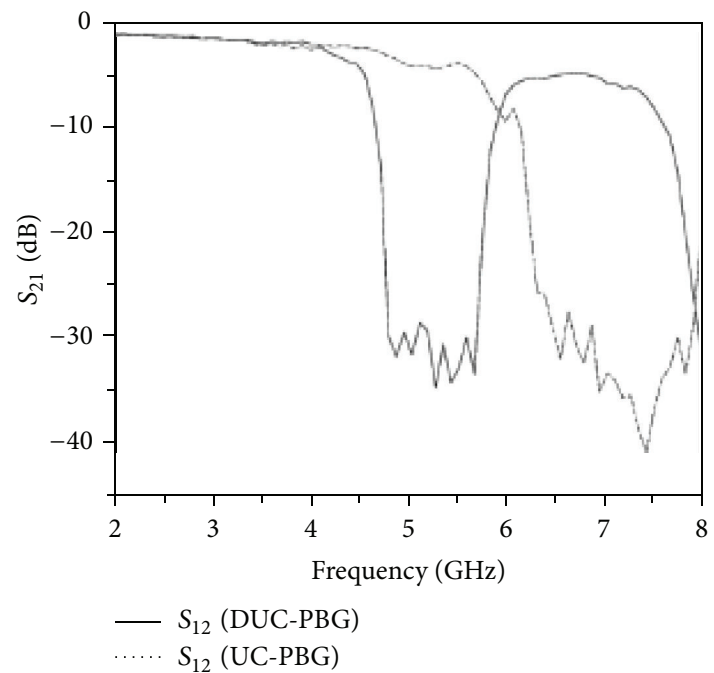

(c)

Figure 7: (a) A unit cell of the conventional UC-PBG and the proposed DUC-PBG. Transmission responses $\left(S_{21}\right)$ of the EBG structures: (b) microstrip line on same layer and (c) microstrip line on another layer.

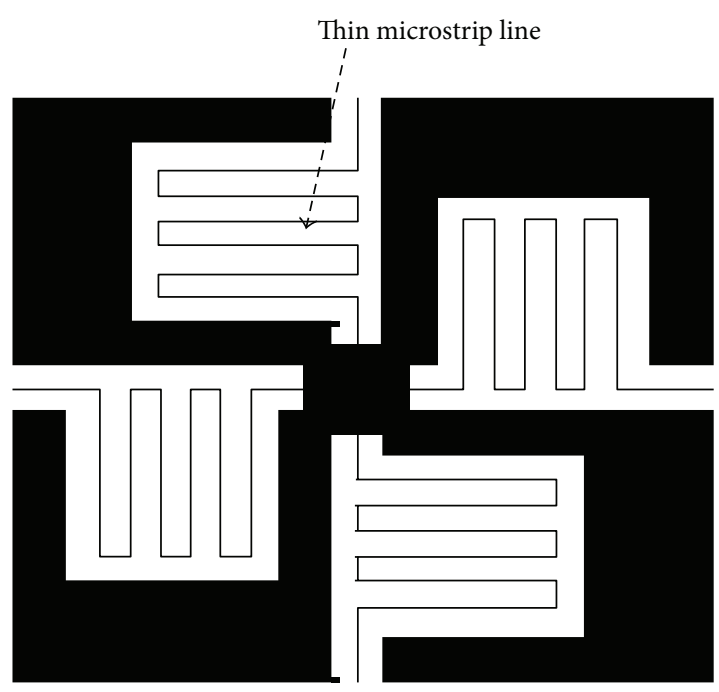

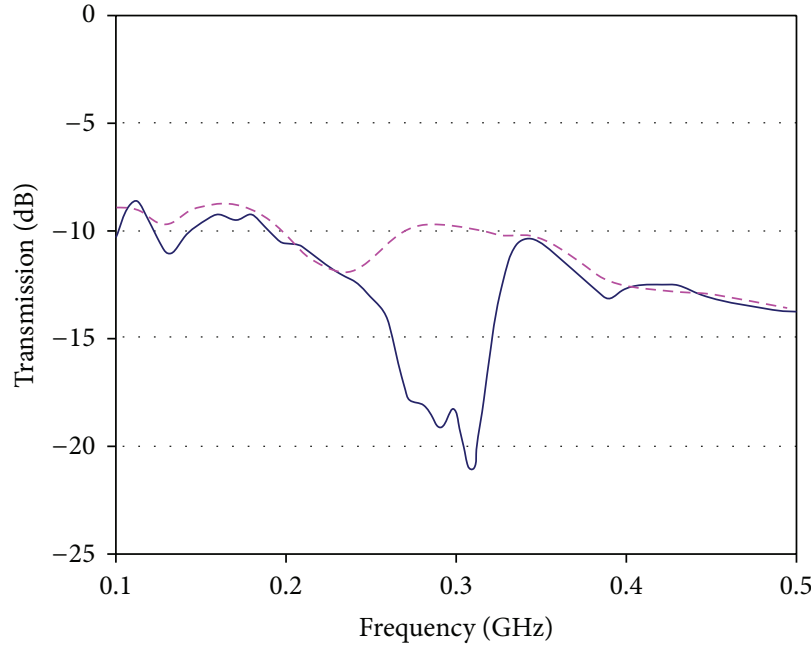

TE surface waves

Ground plane only (a)

FIGURE 8: (a) Schematic of the small EBG structure with thin microstrip line developed on $1.6 \mathrm{~mm}$ FR4 and (b) transmission responses $\left(S_{21}\right)$. 


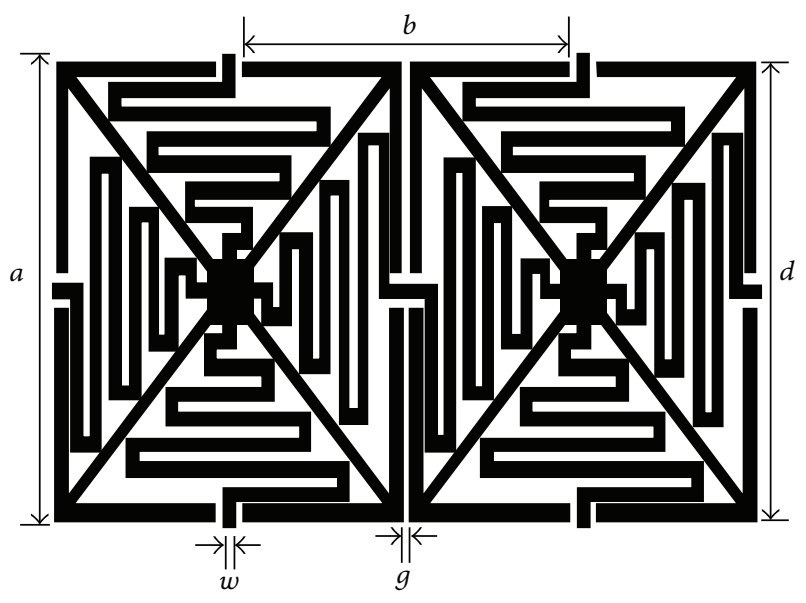

(a)

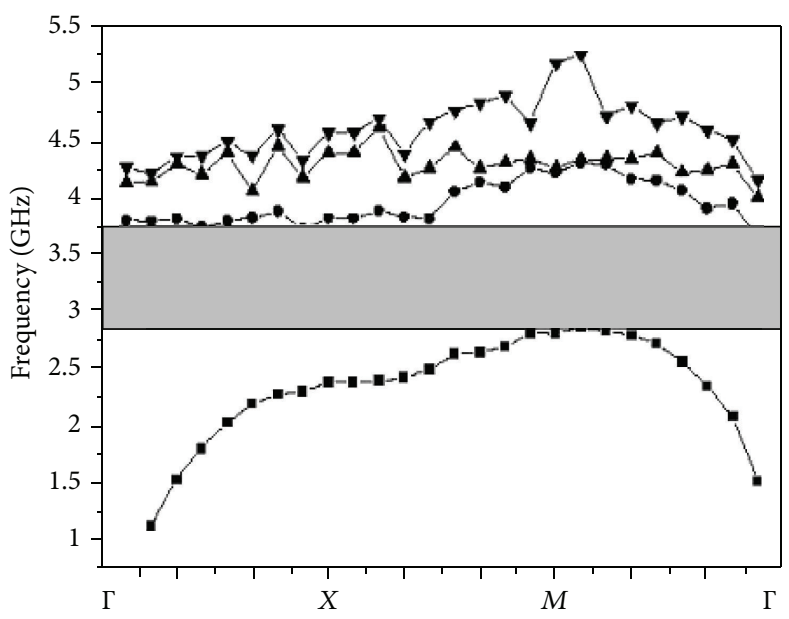

(b)

Figure 9: (a) The ameliorated UCEBG and (b) dispersion diagram.
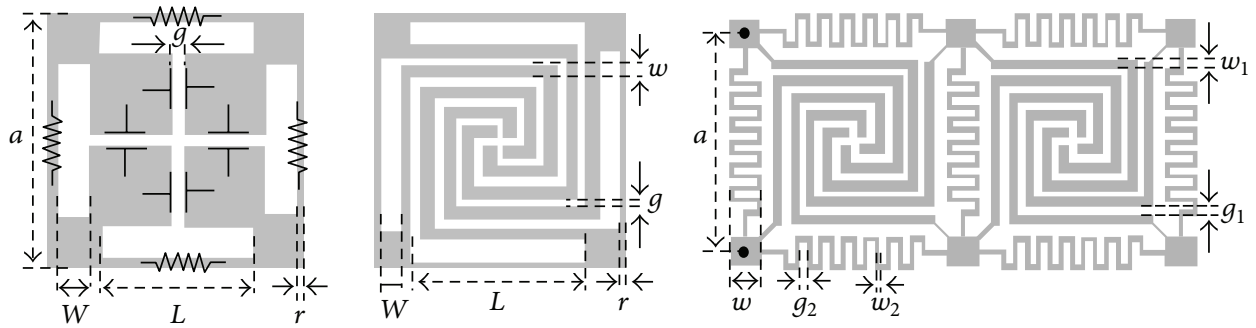

(a)

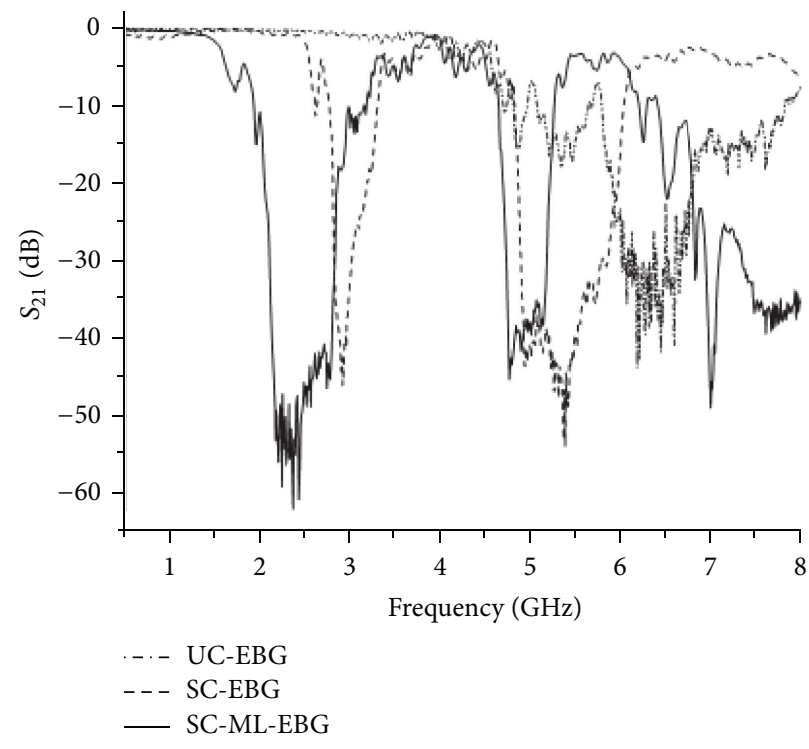

(b)

Figure 10: (a) Successive modification from a regular shape UC-EBG to SC-ML-EBG and (b) their transmission responses $\left(S_{21}\right)$.

the radiation pattern control [62]. EBG structure is also an attractive solution to reduce the power loss through the substrate of a conventional antenna $[4,63]$. Generally, EBG structure produces a smoother radiation profile, lower back radiation, and higher gain and efficiency than a conventional ground antenna. Moreover, these structures would ensure low interference with adjacent microwave elements and act as a shielding material between the antenna and the user of communications device [2, 27, 30]. Furthermore, an EBG object could drive the microstrip antenna to a dual frequency 


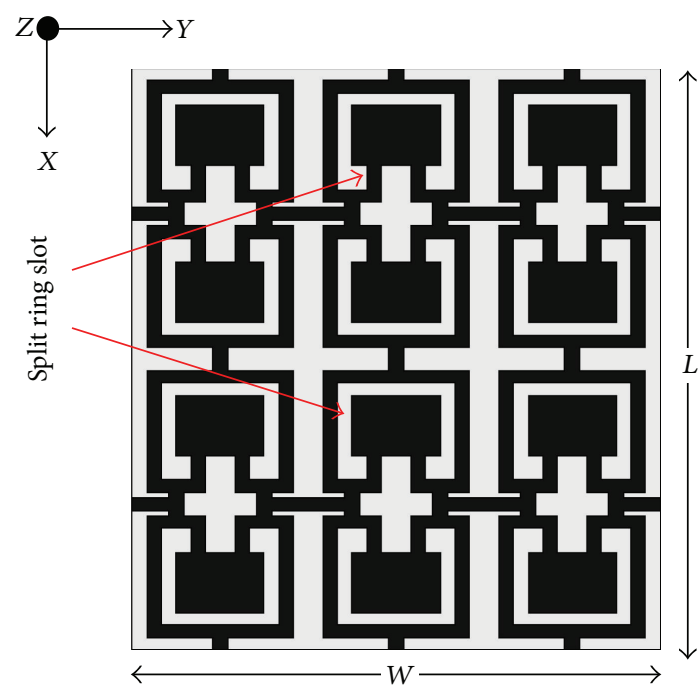

(a)

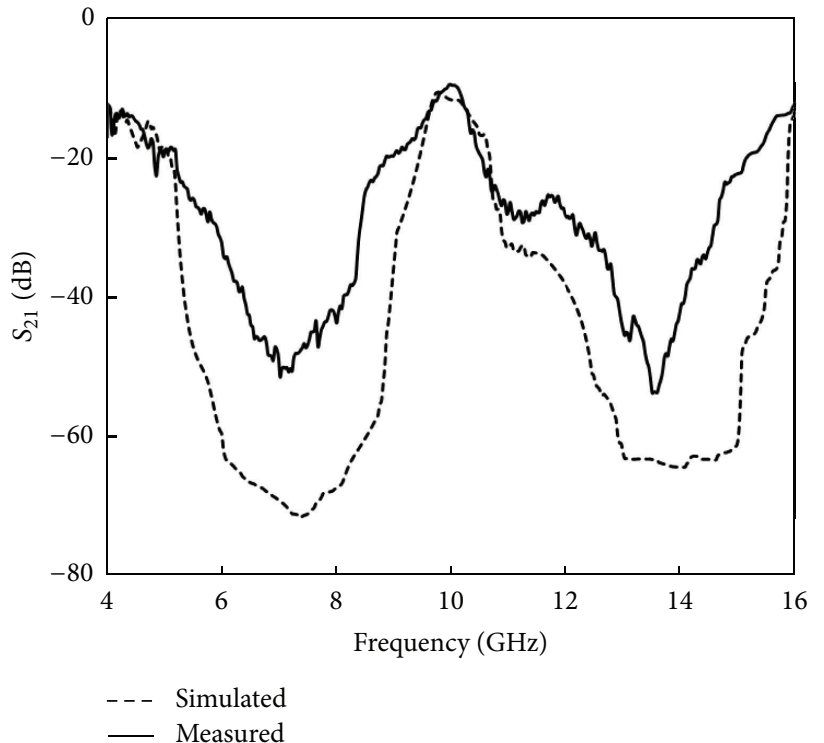

(b)

FIgURE 11: Dual-band SRS-EBG: (a) EBG structure and (b) transmission responses $\left(S_{21}\right)$.

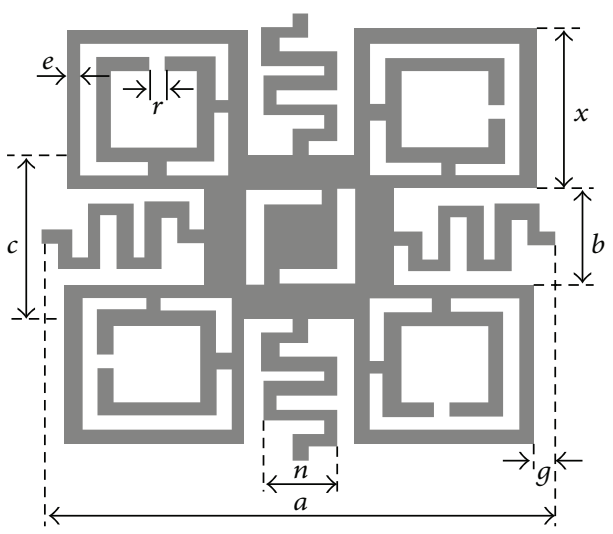

(a)

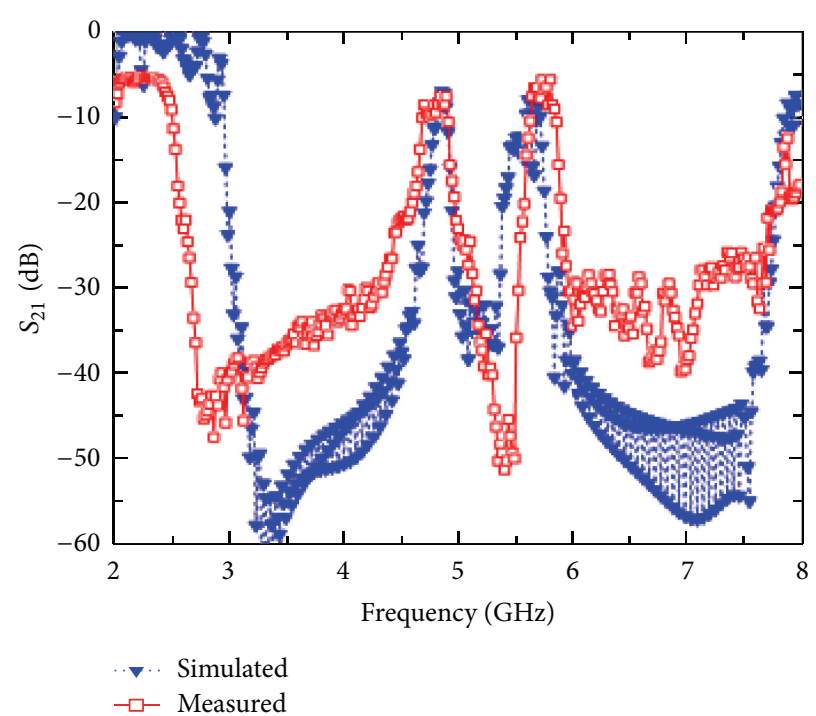

(b)

Figure 12: A triple band EBG: (a) unit cell and (b) transmission characteristics $\left(S_{21}\right)$.

operation modifying the higher order radiation patterns, thus making them similar to those of the basic mode [64]. Besides the antenna element applications, EBG structures have also been used in arrays to alleviate the mutual coupling effects [21, 65]. Strong mutual coupling could reduce the array efficiency and cause the scan blindness in phased array systems. The EBG structures are efficient to reduce the mutual coupling and eliminate the scan angle $[37,63]$.

Application of UC-EBG to microstrip antennas is an attractive research topic; however, many issues arises since two different structures are to be integrated together for achieving enhanced performances. Some of the recent EBG designs and their application to enhance microstrip antenna performances are discussed below.

5.1. EBG Structures with Microstrip Antenna Element. In 1999 , Coccioli et al. [40] applied the first UC-EBG structure [26] to improve an aperture coupled patch antenna performance. Figure 13 shows a photograph of the antenna surrounded by a UC-EBG structure and its return loss characteristics. The patch is etched on a standard $50 \mathrm{mil}(1.27 \mathrm{~mm})$ thick substrate with a dielectric constant of 10.2. The patch size is $210 \mathrm{mil} \times 100 \mathrm{mil}$, resulting in a resonant frequency at $12 \mathrm{GHz}$. 


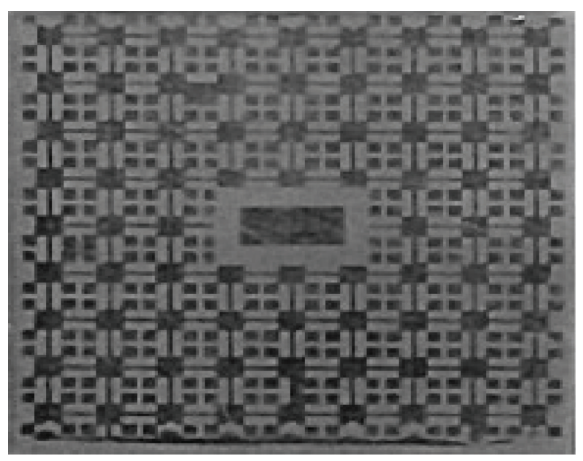

(a)

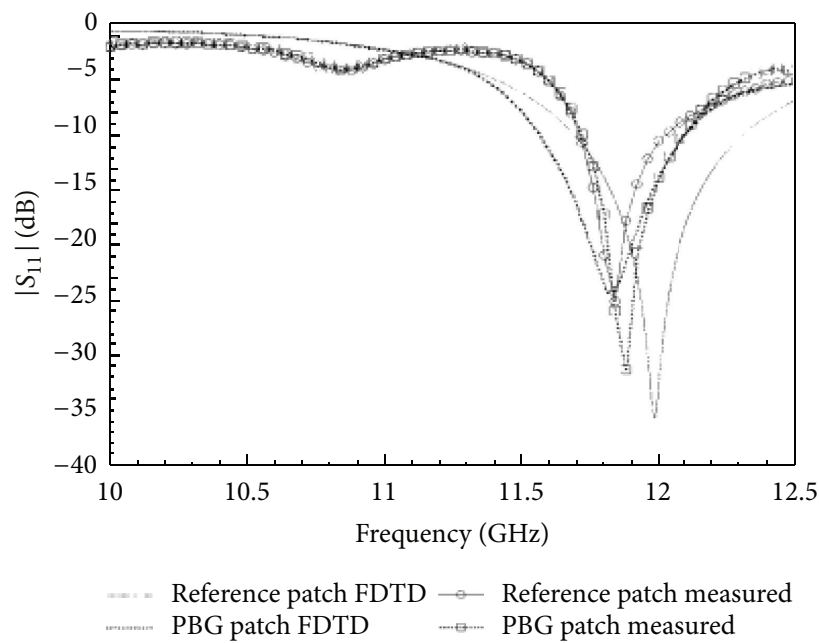

(b)

FIGURE 13: (a) An aperture coupled patch antenna surrounded by UC-EBG cells and (b) its return loss characteristics.

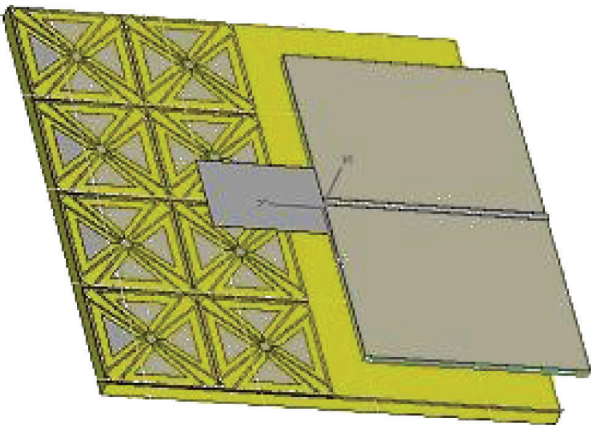

(a)

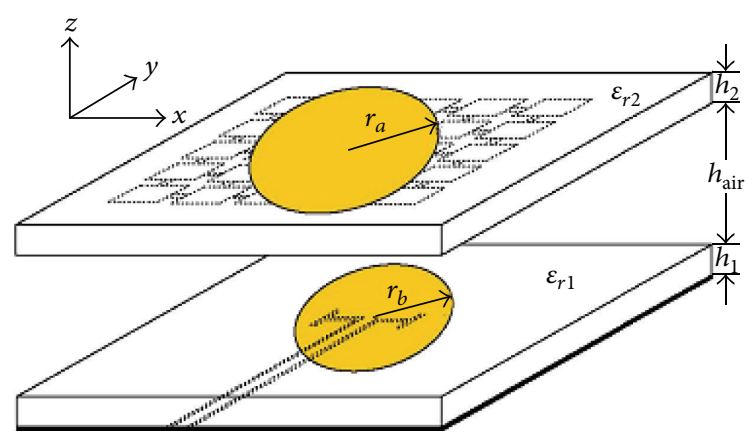

(b)

FIGURE 14: EBG with microstrip antenna: (a) monopole over bow-tie EBG and (b) stacked CPW-fed circular microstrip antenna over rectangular EBG.

The patch is surrounded by three rows of UC- EBG cells, and a 50 mil gap is left between the patch and UC-EBG pattern. Measured data show achievement of a more focused beam radiated in the broadside direction with over $3-\mathrm{dB}$ gain enhancement.

A dual band monopole antenna placed over a double bow-tie EBG structure was investigated by Folayan and Langley $[41,66]$ in 2006. As shown in Figure 14(a), the total volume of the antenna is $180 \times 180 \times 8 \mathrm{~mm}^{3}$ including the $2 \mathrm{~mm}$ air gap in between two $3.5 \mathrm{~mm}$ FR4 dielectric materials (permittivity $=4.4$ ). The $4 \times 4 \mathrm{EBG}$ array consists of $22.3 \times 22.3 \mathrm{~mm}^{2}$ unit cells. Because of the reflection property, the back lobe was reduced by $5 \mathrm{~dB}$, while the bandwidth preserved to $11 \%$ and $6 \%$, slightly less than the antenna alone. In 2008, Chayono et al. [67] investigated a dual band CPWfed circular microstrip antenna over a planar EBG structure as shown in Figure 14(b). The air gap was chosen to be $5 \mathrm{~mm}$, and the total antenna size is $30 \times 30 \mathrm{~mm}^{2}$. Rectangular patches with interconnecting strips were used to realize the EBG reflecting surface. The stacked antenna achieved two bandwidths of $6.73 \%$ and $7.55 \%$, respectively, with an average gain of $7.8 \mathrm{dBi}$. However, the antennas are not sufficiently low profile.

In 2010, Mantash et al. [68] designed another dual band CPW-fed multilayer EBG antenna as shown in Figure 15. The G-shape antenna size is $67.35 \times 25.6 \mathrm{~mm}^{2}$ and printed on a $1.575 \mathrm{~mm}$ Neltec NY9220 substrate (permittivity $=2.2$ ). The EBG structure is constructed with concentric square rings of $28.5 \times 28.5 \mathrm{~mm}^{2}$ and built on the same substrate of antenna with $3.15 \mathrm{~mm}$ thickness. Including the air gap, total EBG-antenna size became $85.5 \times 85.5 \times 5.725 \mathrm{~mm}^{3}$, which shows narrower bandwidth than the G-antenna's operating bandwidth. However, the gain is enhanced at some points whilst fluctuations are observed, even the gain falls down to negative values at some points. To improve this situation, they rotated the EBG position by $45^{\circ}$ with respect to the antenna positions and this eliminated the dip but lowered the average gain to $6 \mathrm{~dB}$. The antenna operates at $2.5 / 5.4 \mathrm{GHz}$ bands, which is expected to be more compact and have smoother gain patterns as it is integrated to an EBG/HIS surface.

The EBG or combination of different EBG structures is also used for impedance matching and harmonic suppression 

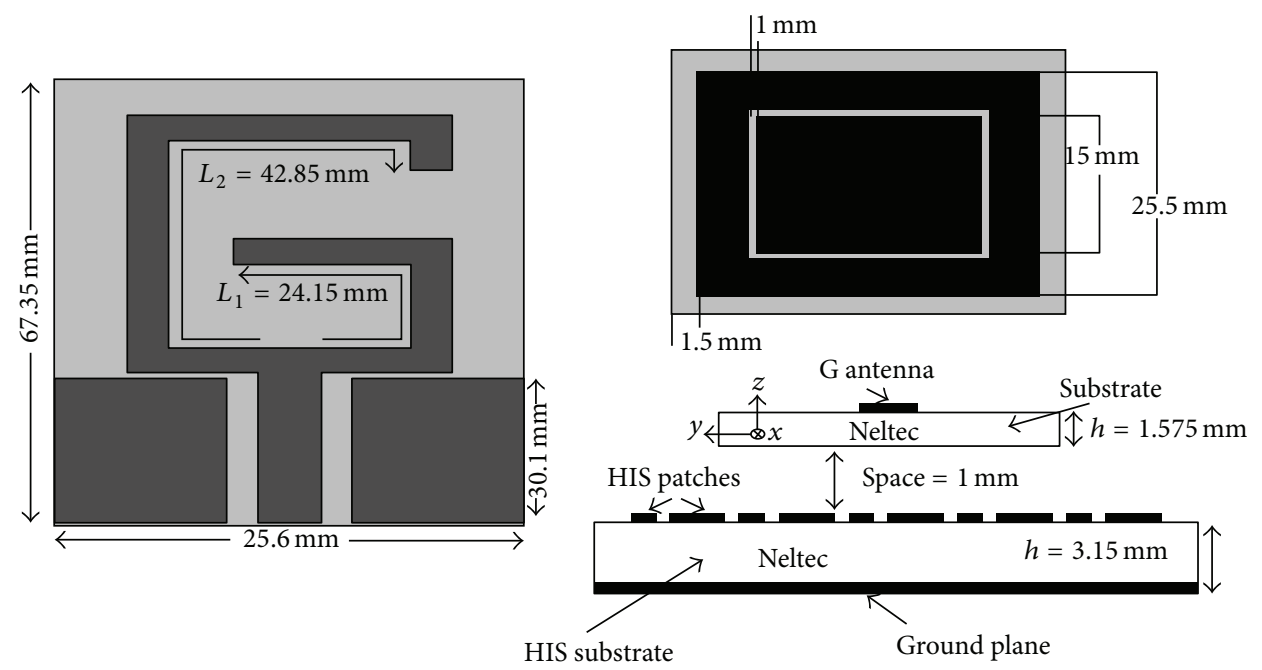

(a)

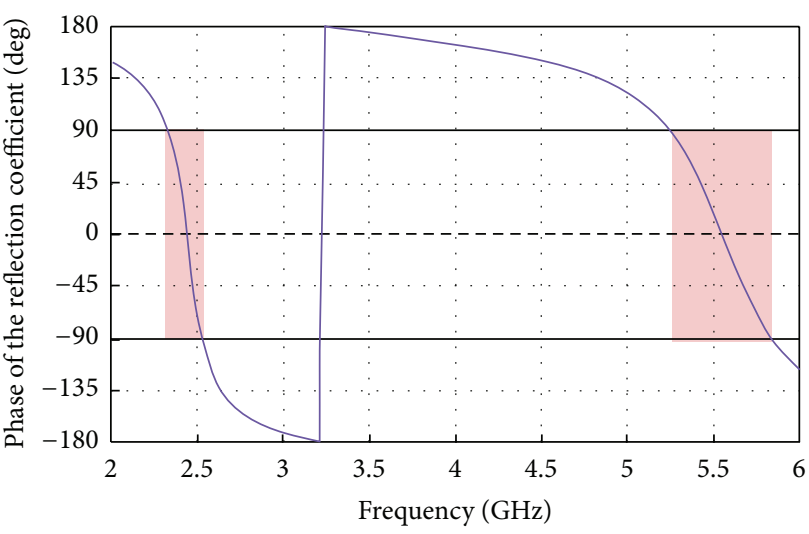

(b)

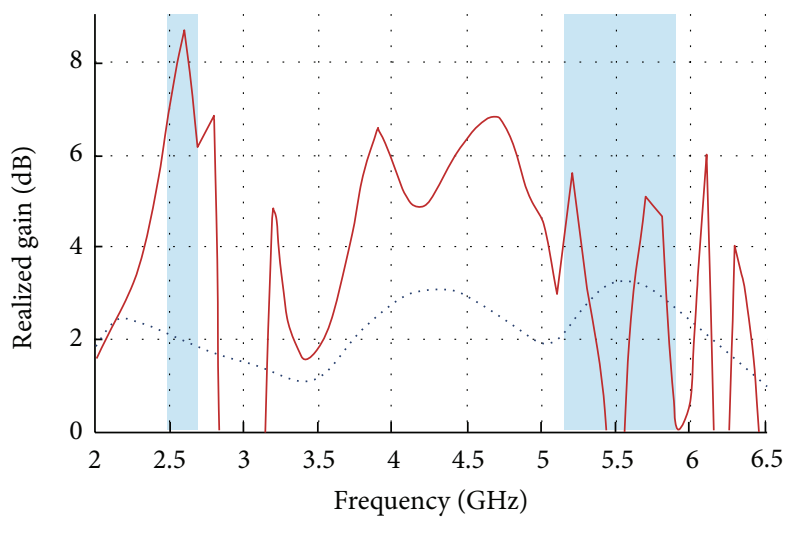

Ant $\mathrm{G}$

- Ant G + EBG

FIGURE 15: (a) G-shape antenna with concentric square EBG structure, (b) reflection phase of the EBG, and (c) comparison of realized gain.

in microstrip antennas $[69,70]$. Recently, a twin patch array has been examined by etching inverse E-shape patterns on the feedline which they referred to as "dummy EBG pattern" [69] because of its resemblance in certain properties and behavior to a conventional EBG structure. A $0.381 \mathrm{~mm}$ thick substrate with relative permittivity of 2.33 is used in this design, and a $2 \times 4$ dummy EBG array is etched on the connecting feedline of the two patches. Referring to Figure 16, the dualpatch array operates at $14.8 \mathrm{GHz}$, and the dummy EBG cells increased its bandwidth from 0.256 to $0.381 \mathrm{GHz}$ with deeper return loss level. The dummy patterns provide better impedance matching without any extra matching circuitry. The radiation performances are not much changed due to the dummy EBG cells; however, the gain and radiation efficiency are increased by $0.23 \mathrm{dBi}$ and $0.37 \%$, respectively.

In 2005, Sung and Kim [70] examined the effect of two different kinds of EBG structures on a microstrip antenna, separately. The compact microstrip resonant cell (CMRC) on the feed line and the defected ground structure (DGS) cell (similar to EBG but etched on the ground only) are studied to obtain impedance matching and harmonic suppression. The DGS size is $18.8 \times 16 \mathrm{~mm}^{2}$, and the CMRC cell size is $23 \times 2 \mathrm{~mm}^{2}$, etched on the top and bottom layer of a 62 mils $(1.575 \mathrm{~mm})$ thick substrate (permittivity $=2.2$ ), respectively. The EBG designs and their effects on the antenna are depicted in Figure 17. The CMRC provides better matching of impedance, while the DGS suppressed the harmonics at 3.6 GHz. Though slight resonance shifting and gain reduction are observed in case of the DGS; CMRC preserved almost the same bandwidth, resonance, and gain as the reference antenna. However, large back lobe was introduced by DGS, probably it acts as a slot antenna and radiates in the backward direction.

Another investigation accomplished by Liu et al. [71] considered the simultaneous effect of DGS-EBG on a $76 \times$ $76 \mathrm{~mm}^{2}$ rectangular patch, as depicted in Figure 18(a). The DGS cell is etched on the ground just below the feedline and covers an area of $32.5 \times 32.8 \mathrm{~mm}^{2}$. On the other hand, 


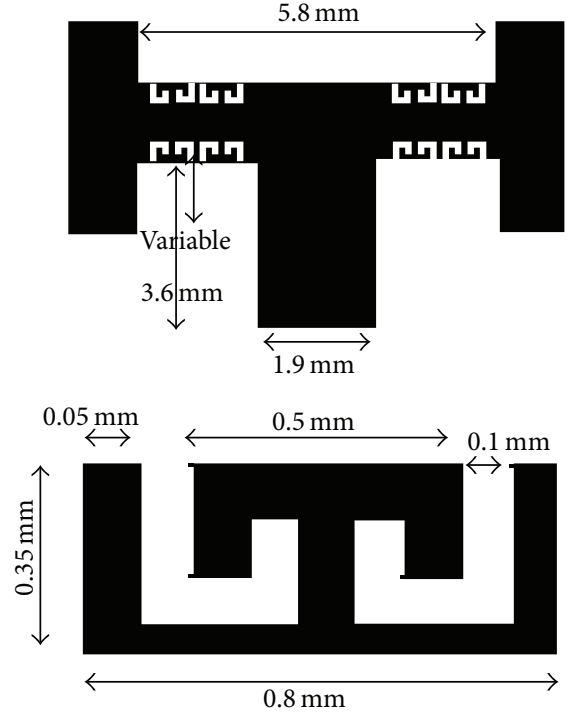

(a)

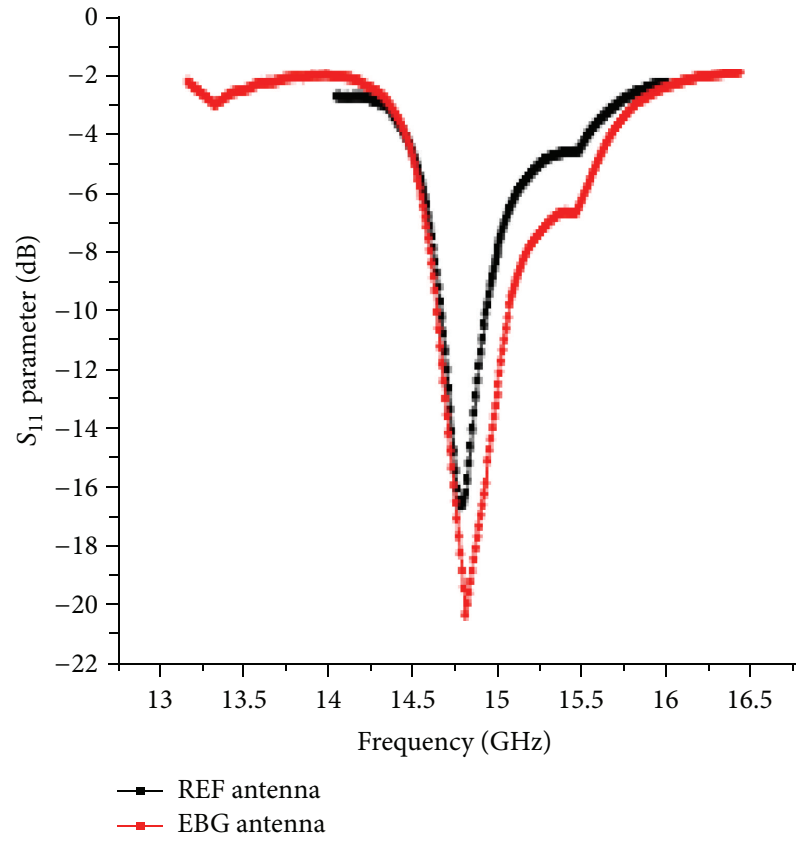

(b)

Figure 16: (a) Top: "dummy EBG" on feedline and bottom: magnified view of the EBG pattern; (b) measured $S_{11}$ parameters for reference and EBG antenna.
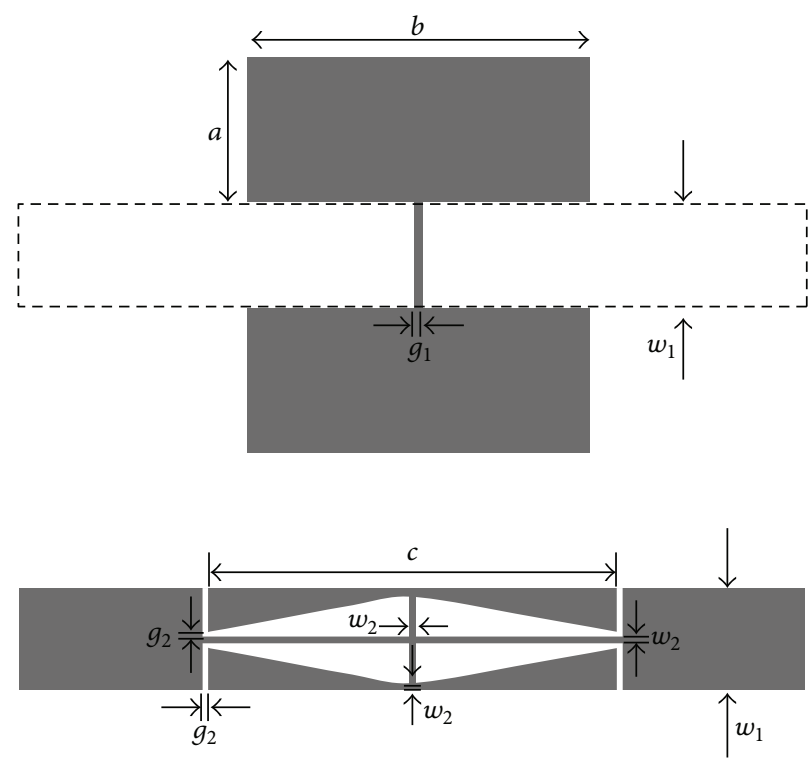

(a)

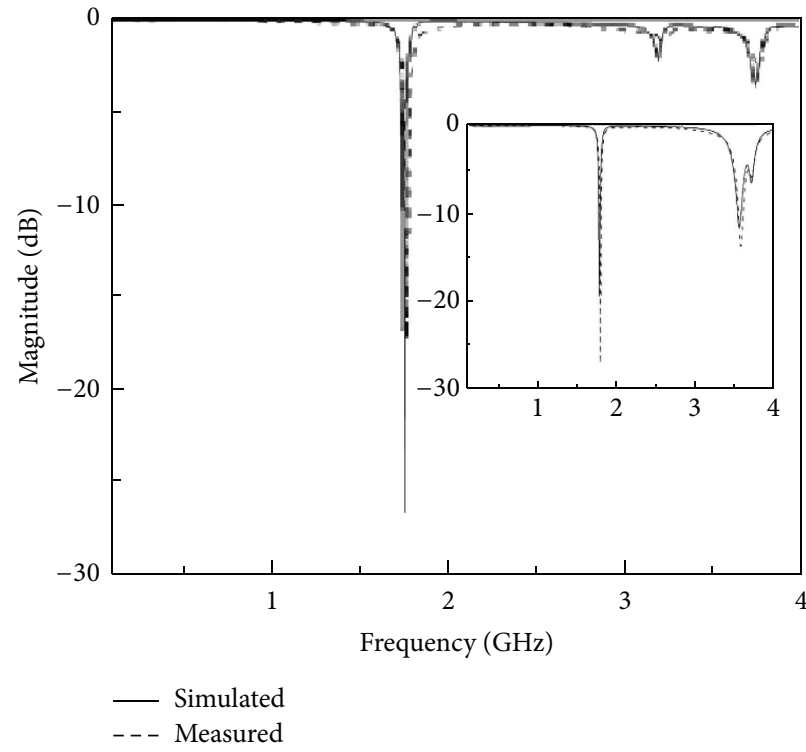

(b)

FIGURE 17: (a) 1-D EBG structures: top is DGS, and bottom is CMRC cell; (b) suppression of the second harmonic at $3.6 \mathrm{GHz}$.

the EBG which is $3 \times 3$ array of circle of $18 \mathrm{~mm}$ radius is etched below the patch area. The total antenna is built on a $1.6 \mathrm{~mm}$ FR4 substrate (permittivity $=4.8$ ) and has two stop bands of $0.81 \mathrm{GHz}$ and $1.26 \mathrm{GHz}$, respectively. The DGS and EBG structures assist to achieve good impedance matching while reducing the second and third harmonics successfully, as depicted in Figure 18(b).
Beside the above discussed configurations, completely planar EBG microstrip antennas was also reported very recently $[38,72,73]$. The SRS-EBG proposed by Alam et al. [38] was investigated as an artificial ground plane for an umbrella shape monopole antenna, which provided a wider bandwidth (from $9.26 \%$ to $11.25 \%$ ), deeper return loss (from -26 to $-31 \mathrm{~dB}$ ), and higher gain (from 4 to $5.5 \mathrm{~dB}$ ) than that 


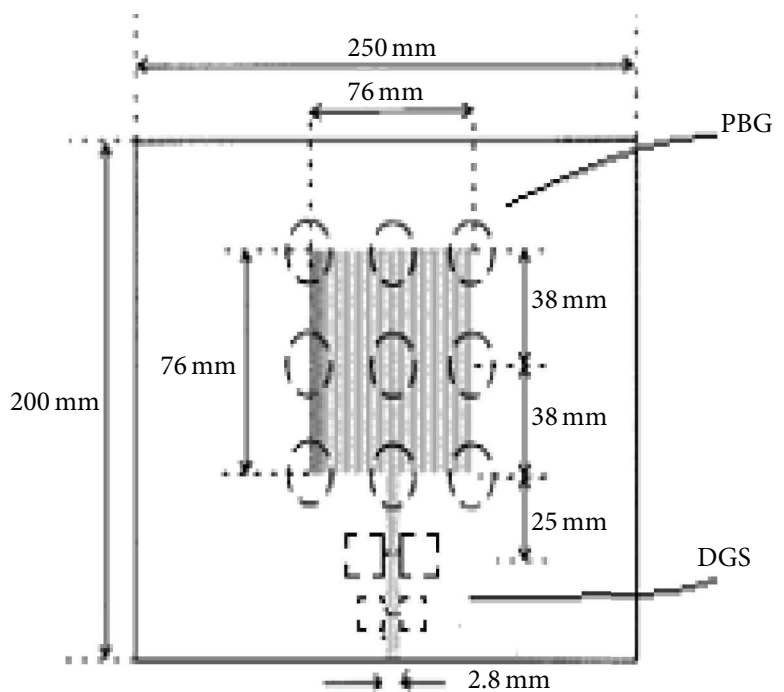

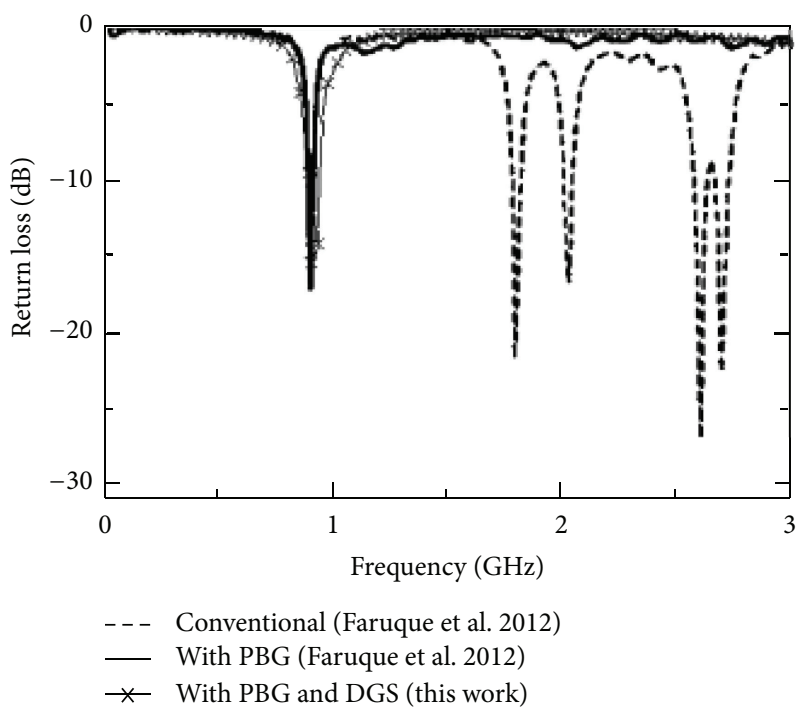

(b)

FIGURE 18: Harmonic suppression of a patch antenna by DGS and EBG.
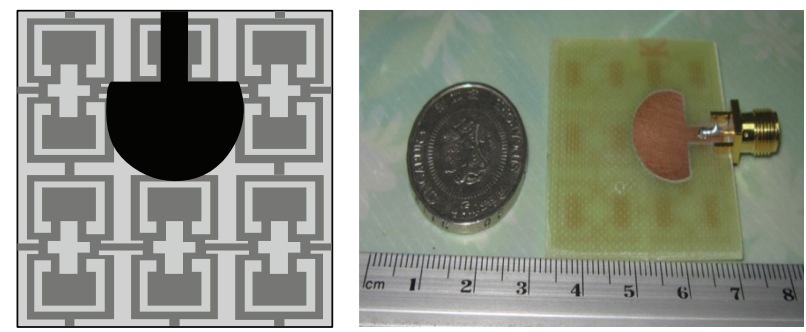

(a)

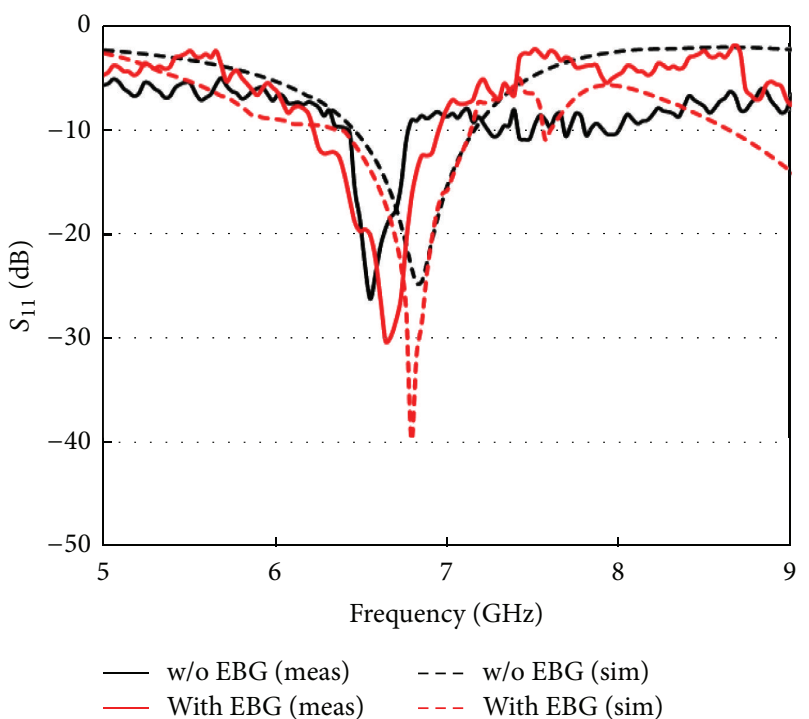

(b)

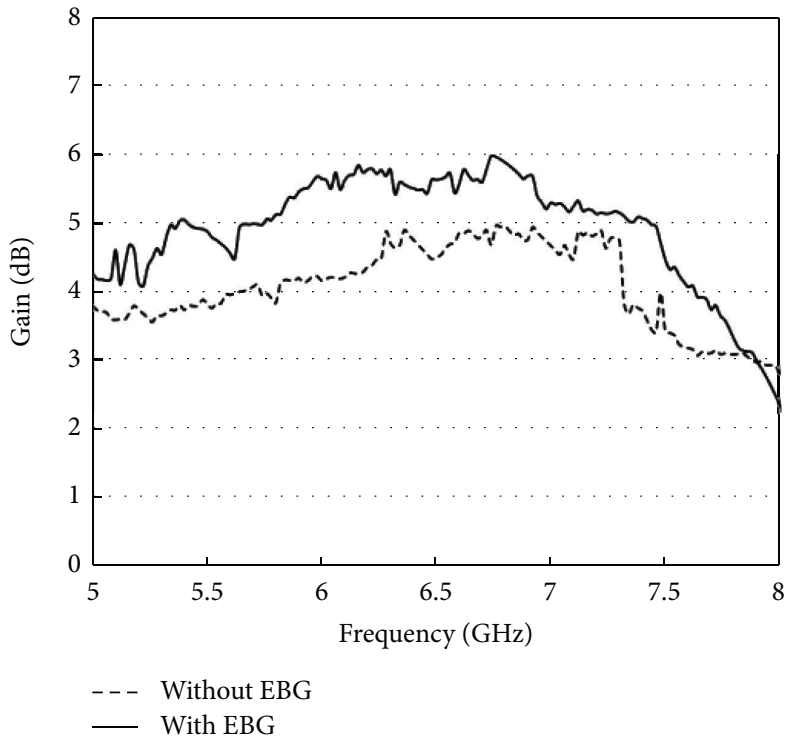

(c)

FIGURE 19: (a) An umbrella shape monopole with SRS-EBG as ground plane, (b) return loss characteristics, and (c) gain comparison. 

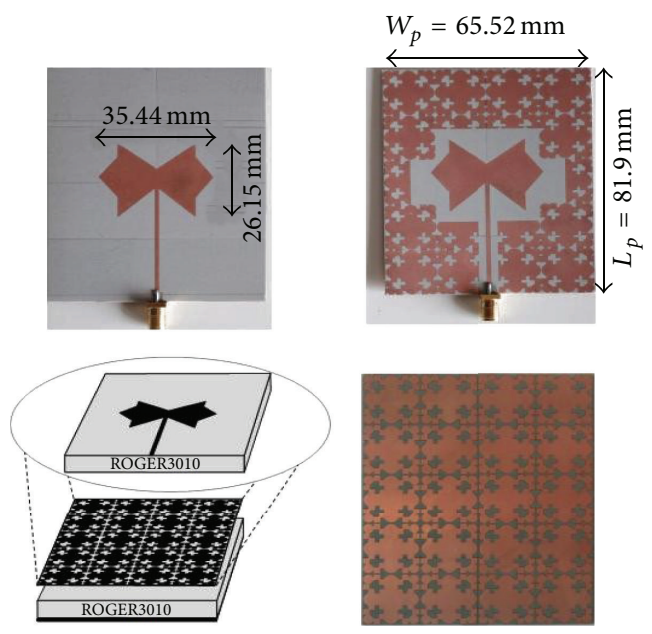

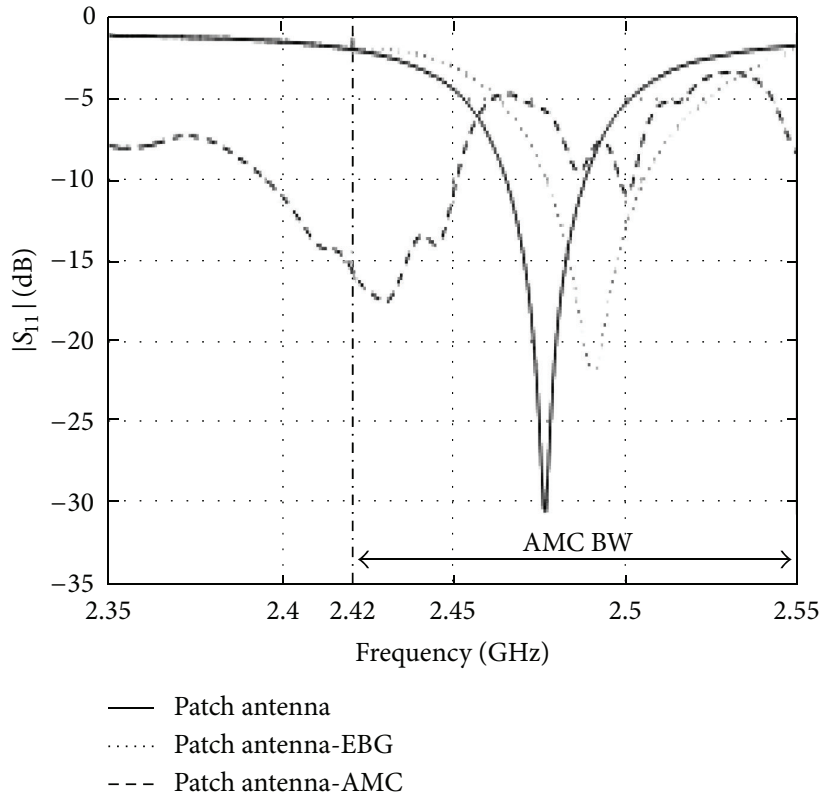

(b)

FIGURE 20: (a) In clockwise: reference antenna, EBG-antenna, AMC surface, and AMC antenna; (b) comparison of their return loss characteristics.

of the antenna with a classical ground plane. The proposed antenna configuration and their performances are shown in Figures 19(a) to 19(c).

A high-impedance periodic structure can be treated as an AMC or EBG, depending on their certain properties. Hadarig et al. [72] examined a microstrip antenna with same EBG structure in two ways-surrounding the patch antenna (EBG) and replacing the ground plane with the same structure (AMC). To apply as a ground plane, reflection phase characteristics are tested whilst transmission band gap is determined by the suspended microstrip line method to surround the patch. Without changing the overall size, a $4 \times 5$ array of AMC cells (unit size $16.93 \times 16.93 \mathrm{~mm}^{2}$ ) was applied as a ground, and then a $4 \times 4$ array of EBG cells (unit size $16.38 \times 16.38 \mathrm{~mm}^{2}$ ) surrounding the patch is investigated. The cell size is adjusted to have stop band center frequency nearly to antenna resonant frequency $(2.5 \mathrm{GHz})$. In the AMC case, the substrate thickness is doubled, hence the capacitive effect, which in turn increases the bandwidth from $20 \mathrm{MHz}$ to $46 \mathrm{MHz}$ and lowers the resonance. In contrast, the surrounding EBG cells increase the antenna bandwidth to $34 \mathrm{MHz}$ due to the coupling resonator effect. The antenna configurations and their measured return losses are shown in Figure 20, whereas Figure 21 compares the radiation patterns at their resonances. It is found that the EBG suppressed the surface waves, enhanced radiation characteristics, and improved the antenna gain by $1.2 \mathrm{~dB}$. Conversely, the AMC cannot suppress the surface waves, also substrate height is doubled, and hence it shows poor radiation performances and low gain.

Another interesting study is performed in [73], where dual-band CPW-fed monopole antenna's bandwidths are improved by ground shape modification and EBG structures. The dual band antenna is designed to operate at 2.4 and $5.8 \mathrm{GHz}$ on a $0.762 \mathrm{~mm}$ thick ARLON $25 \mathrm{~N}$ dielectric substrate (permittivity $=3.28$ ). Initially, modification of the coplanar grounds from rectangular to trapezoidal shapes increased the lower and upper bandwidth by $52 \mathrm{MHz}$ and $26 \mathrm{MHz}$, respectively. Then, the patch is surrounded by an array of EBG units $\left(25 \times 25 \mathrm{~mm}^{2}\right)$ which made the antenna size bigger $\left(100 \times 75 \mathrm{~mm}^{2}\right)$. Figure 22 (a) shows the method of suspended line applied to calculate the EBG structures band gap. The resulted transmission responses exhibit multiple band gaps, of which two are nearer to the antenna operating bands. As the resonances of antenna and EBG almost coincide, coupling of resonances broadened the lower band from 246 to $391 \mathrm{MHz}$; however, the upper band is decreased from 601 to $578 \mathrm{MHz}$. The measured return losses for three different antenna arrangements are compared in Figure 22(b). Observing the radiation performances shown in Figure 22(c), it was found that the antenna gain is increased by 1 and $2.4 \mathrm{~dB}$ in both bands, while the radiation efficiencies are increased by $4 \%$ and $9 \%$, respectively.

5.2. EBG Structures Microstrip Antenna Array. Mutual coupling between elements of a microstrip antenna array mostly results from the excited surface waves, and it adversely affects the antenna radiation characteristics. In case of microstrip antennas, E-plane coupling is stronger than the H-plane coupling [63]. Numerous techniques were studied and applied to alleviate mutual coupling in an array that includes cavity backing, partial substrate removal, corrugations, split ring resonators (SRR), defected ground structures (DGS), and electromagnetic band gap structures (EBG) $[9,21,65,74-76]$. 


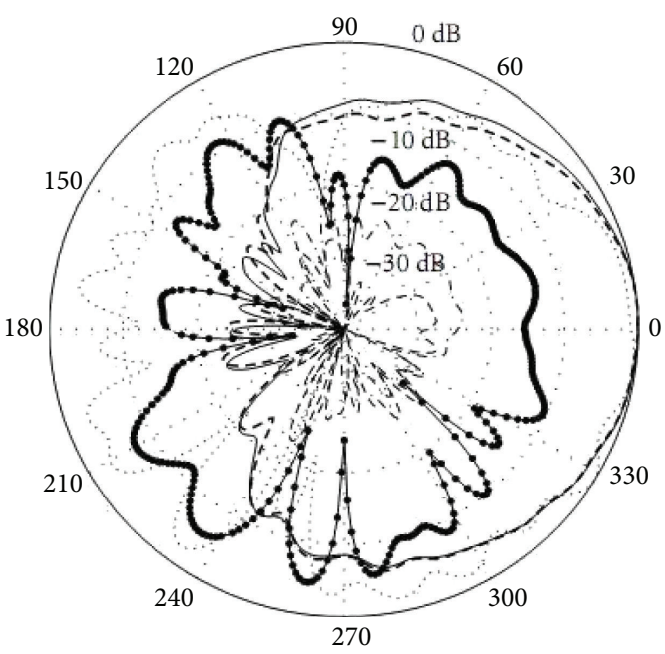

$E$-plane normalized amplitude $(\mathrm{dB})$

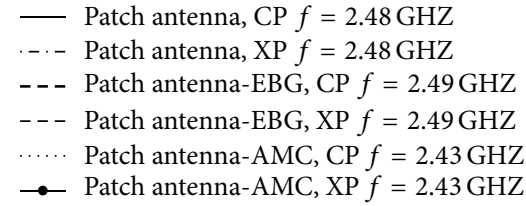

(a)

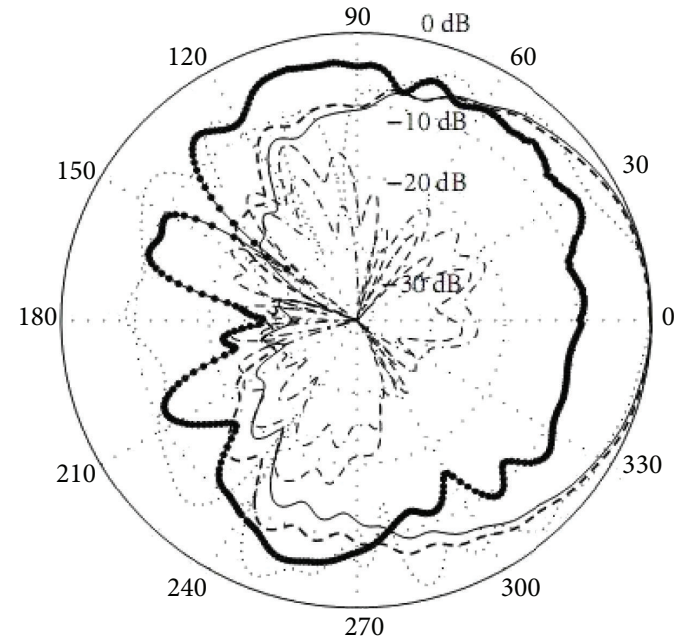

$H$-plane normalized amplitude (dB)

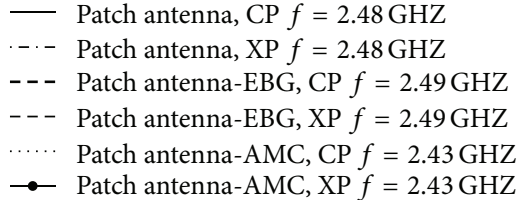

(b)

FIGURE 21: Radiation patterns of the antennas at their resonances.

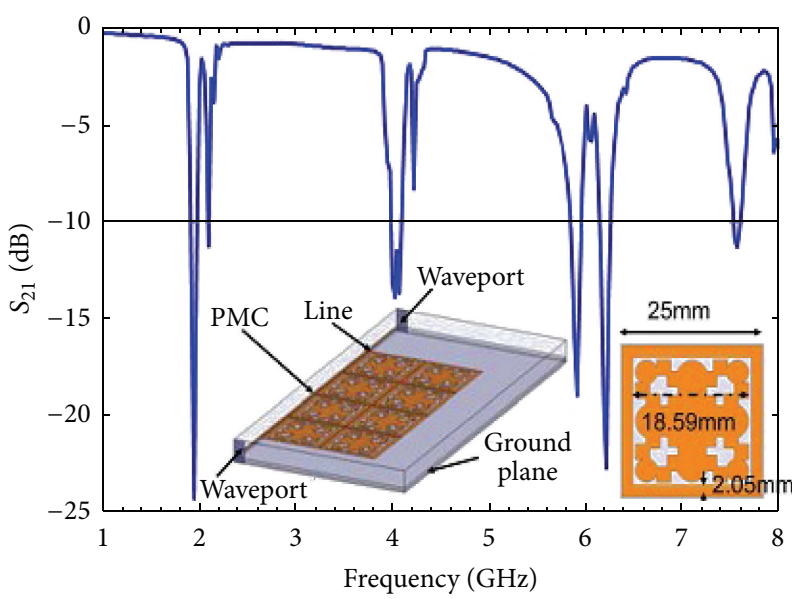

(a)

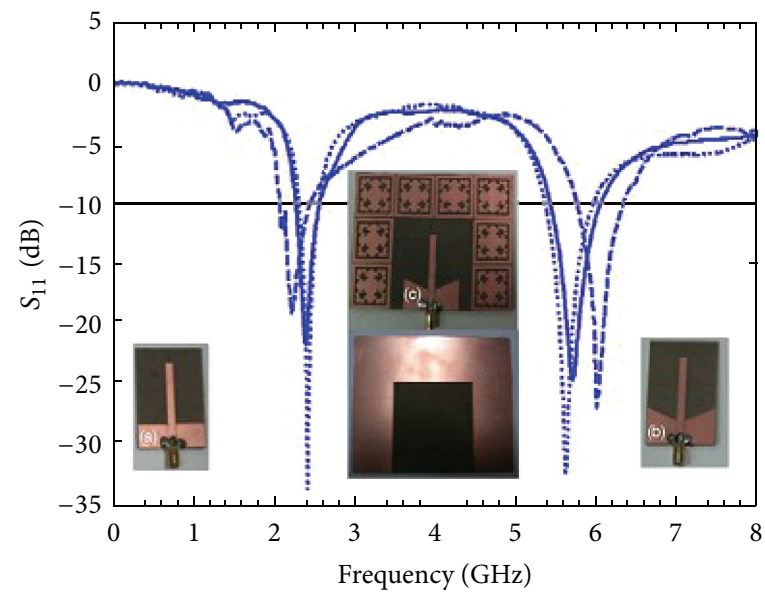

- CPW-fed-monopole-trapezoidal CPW-fed-monopole

(b)

Figure 22: (a) Simulated band gap for a $4 \times 4$ EBG array (b) Measured return losses.

Figure 23 describes the coupling direction in a microstrip antenna array and some coupling reduction techniques. Compared to the other methods, the EBG structures are easy to apply and showed superior performance in reducing mutual coupling $[63,65]$.

In 2003, Yu and Zhang [77] investigated the mutual coupling reduction ability of a newly designed dumbbell
EBG (DEBG) structure by inserting the structure between a microstrip antenna array (MSAA), as shown in Figure 24. A dumbbell shape unit cell has an area of $2.5 \times 8.6 \mathrm{~mm}^{2}$ and consists of two square patches of $2.5 \times 2.5 \mathrm{~mm}^{2}$ with a $0.4 \mathrm{~mm}$ wide and $3.6 \mathrm{~mm}$ long interconnecting line. The stop band of DEBG is adjusted to coincide with antennas operating band at $5.6 \mathrm{GHz}$; hence, the antenna resonance is not much affected 

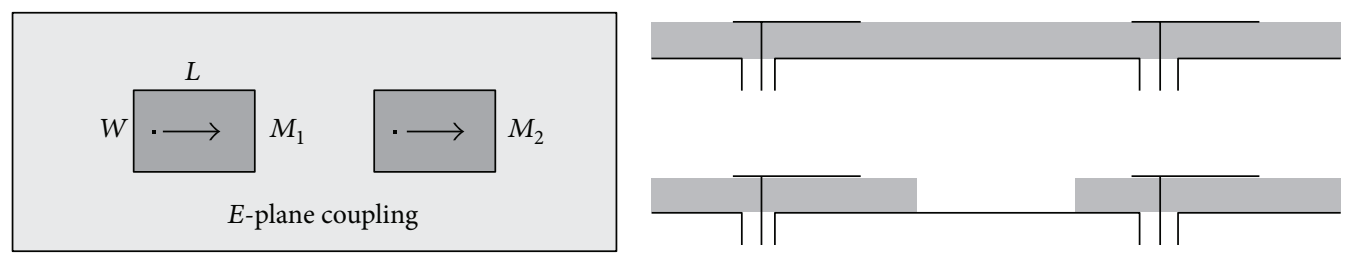

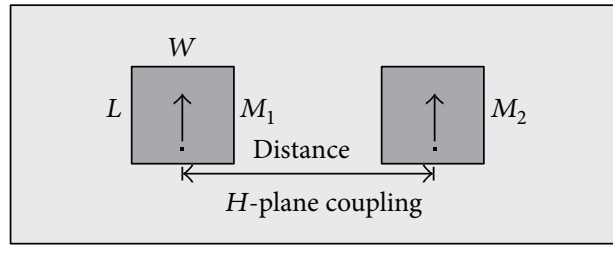

(a)

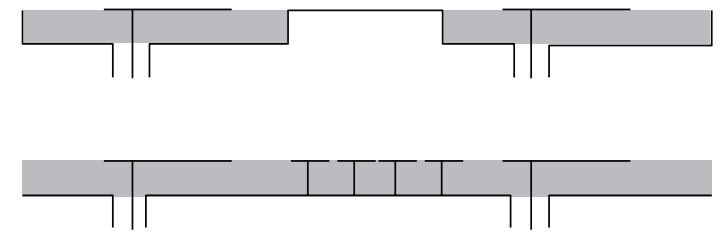

(b)

Figure 23: (a) The coupling direction in probe fed microstrip antenna arrays. (b) Techniques to reduce mutual coupling: normal microstrip array, substrate removal, cavity backing, and EBG structures (from top to bottom).

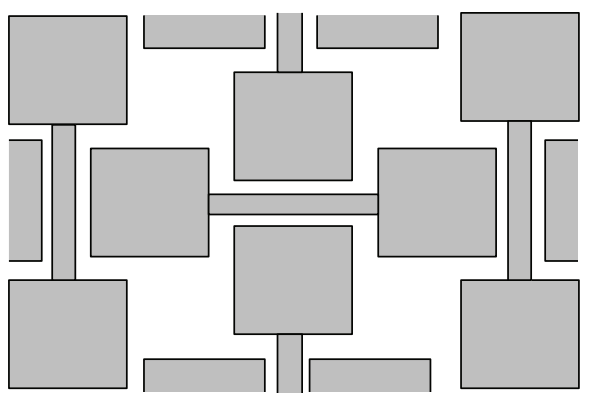

(a)

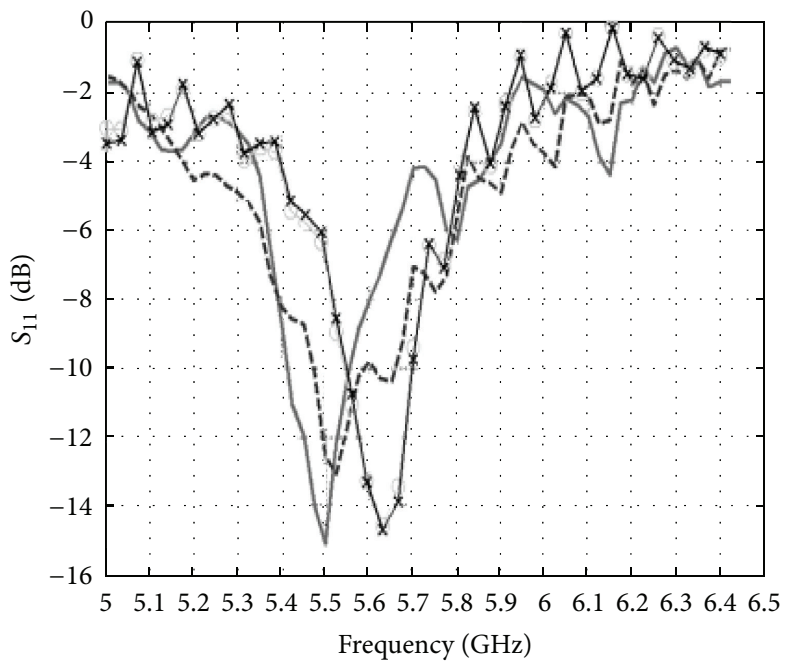

(c)

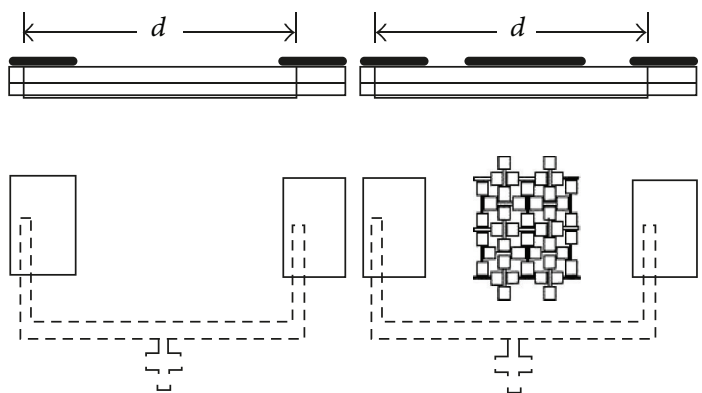

(b)

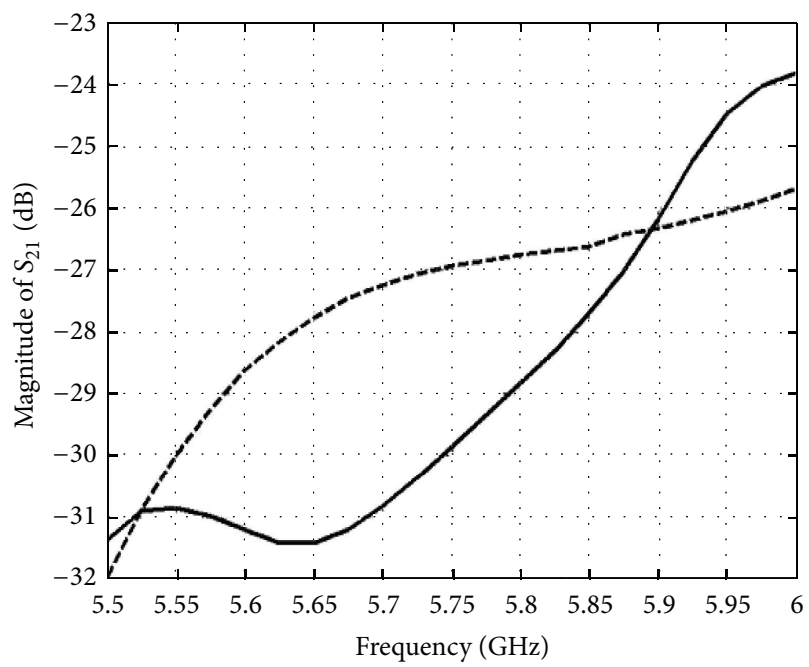

(d)

FIGURE 24: (a) DEBG structure, (b) MSAA with and without DEBG, (c) $S_{11}$ comparison, solid line: measured without EBG, dashed line: measured with EBG, and cross mark line: simulated with EBG, and (d) $S_{21}$ comparison, dashed line: without EBG, solid line: with EBG.

by the DEBG. Here, the antenna distance $(d)$ is considered to be $45 \mathrm{~mm}$, which is $84 \%$ of the free space wavelength $\left(\lambda_{0}\right)$ at $5.6 \mathrm{GHz}$. As compared in Figure 24(d), the DEBG reduced the mutual coupling by $4 \mathrm{~dB}$ at $5.65 \mathrm{GHz}$. The side lobes have decreased from 1.8 to $2.1 \mathrm{~dB}$, and $1 \mathrm{~dB}$ gain improvement is observed.

To obtain more compactness by reducing the patch separation, multilayer dielectric substrate structure was examined 


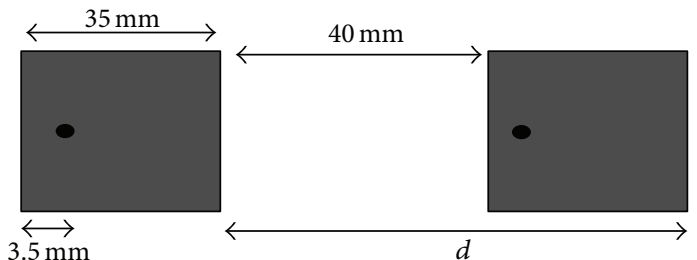

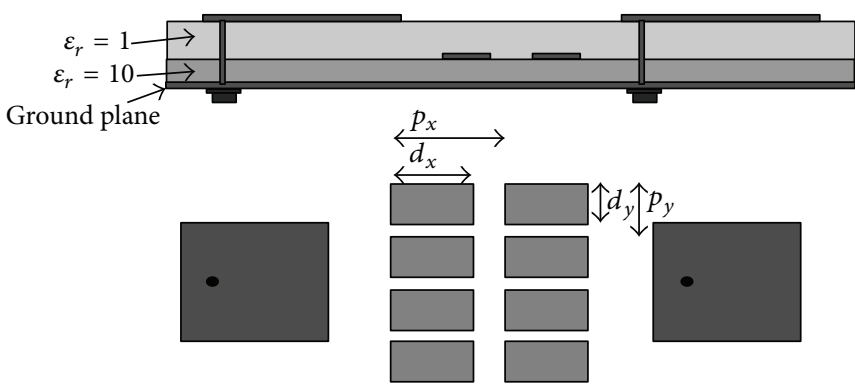

(a)

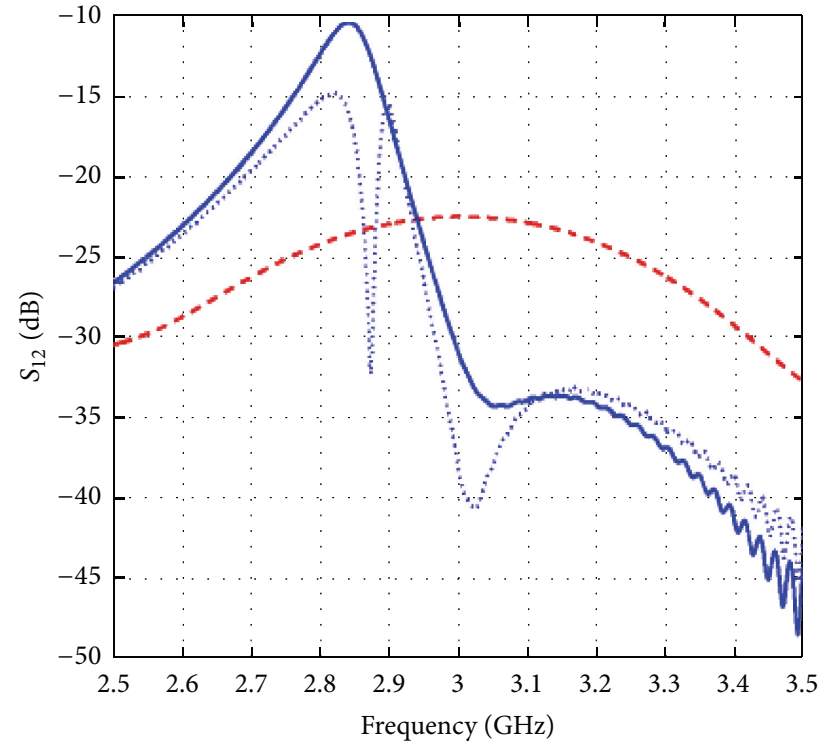

- - $S_{12}$ without EBG

$S_{12}$ with a 8 elem. EBG

$-S_{12}$ with a 4 elem. EBG

(b)

FIGURE 25: (a) Reference array and array with EBG on multilayer dielectric substrate. (b) Mutual coupling comparison of the array.
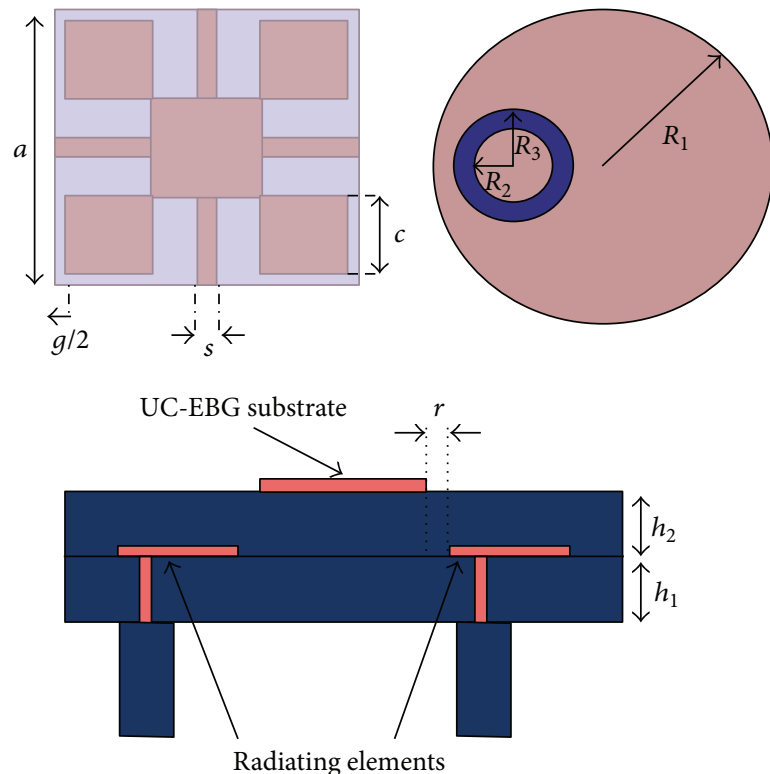

(a)

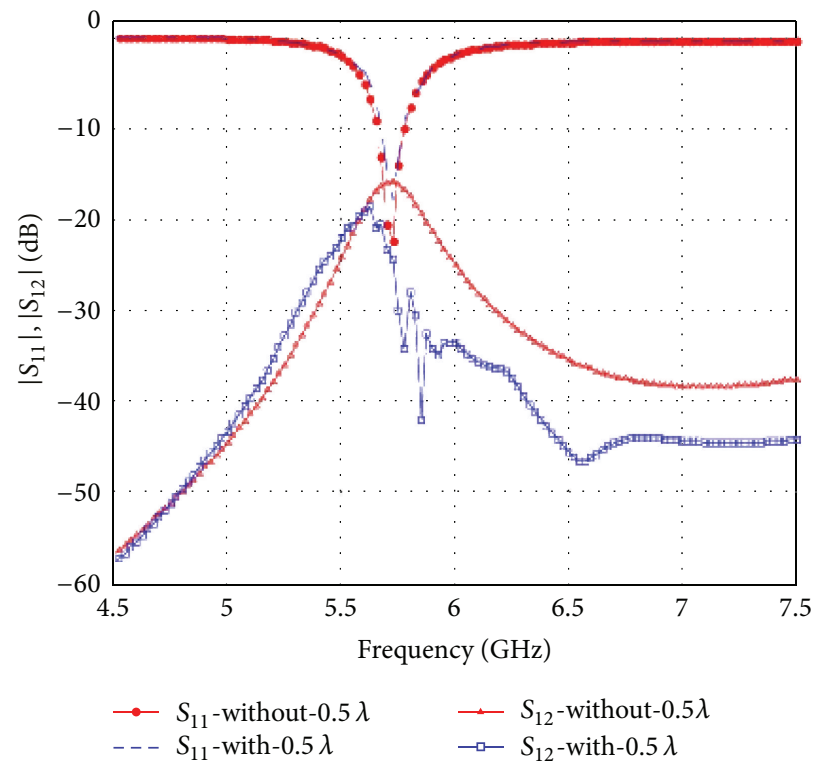

(b)

FIGURE 26: (a) UC-EBG structure on a multilayer configuration and circular microstrip antenna array. (b) $S$-parameters of the array.

by Rajo-Iglesias et al. [76]. The $15 \times 15 \mathrm{~mm}^{2}$ square EBG patches with $5 \mathrm{~mm}$ element spacing are placed on a thin high permittivity material $\left(2.54 \mathrm{~mm}\right.$ and $\left.\varepsilon_{r}=10\right)$ and the antenna on a thick low permittivity material $(6 \mathrm{~mm}$ and $\left.\varepsilon_{r}=1\right)$. The two different materials are integrated such that the antennas are on the top surface, whereas the EBG is sandwiched as shown in Figure 25. The separation between edges is chosen to be $40 \mathrm{~mm}$, and the total separation between elements is $75 \mathrm{~mm}$ which is $0.75 \lambda_{0}$ at $3 \mathrm{GHz}$. With the $25 \times$ $25 \mathrm{~mm}^{2}$ square EBG cells mutual coupling is reduced from $-23 \mathrm{~dB}$ to $-29 \mathrm{~dB}$ ( $6 \mathrm{~dB}$ reduction). Further optimization of the EBG cells to rectangular shapes $\left(20 \times 35 \mathrm{~mm}^{2}\right)$ reduced the mutual coupling to $-35 \mathrm{~dB}$, with an interelement spacing of $0.5 \lambda_{0}$. 


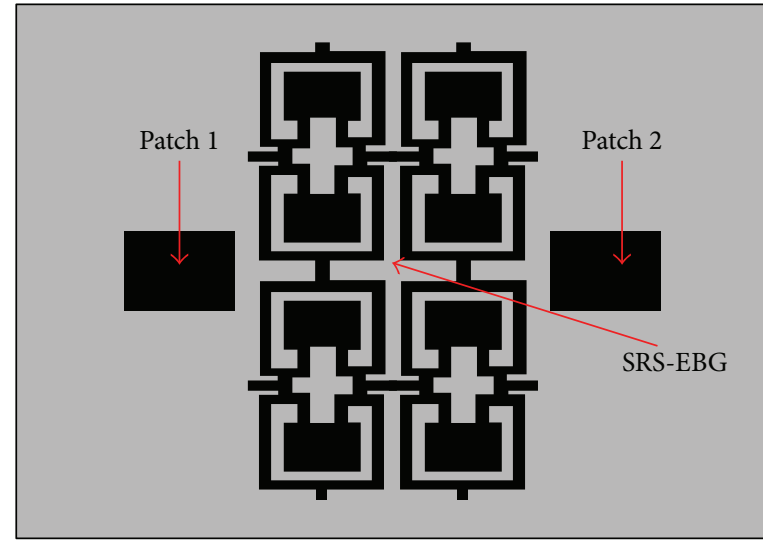

(a)

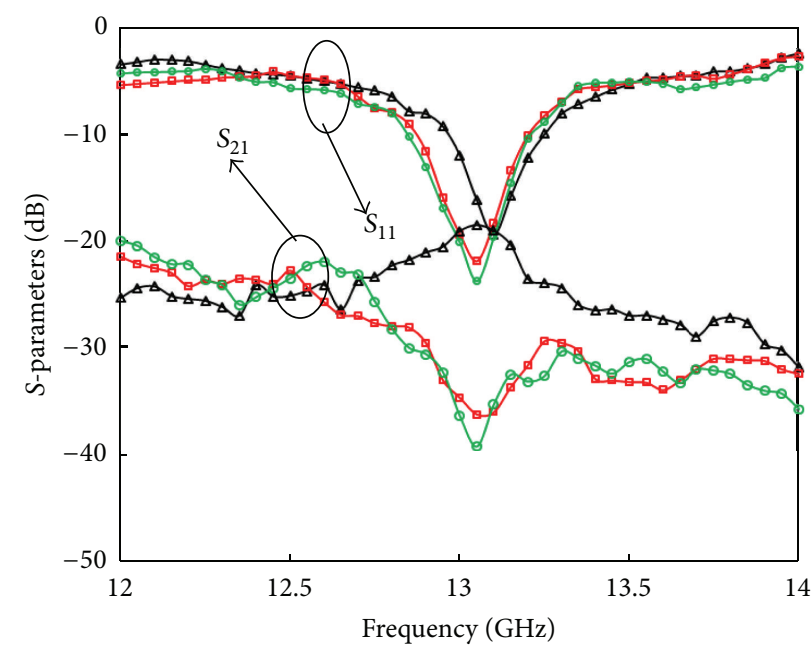

$\begin{array}{ll}\triangle S_{11} \text { (without EBG) } & \left.\square S_{11} \text { (with EBG } 2 \times 2\right) \\ \rightarrow S_{11}(\text { with EBG } 3 \times 2) & \rightarrow S_{21} \text { (without EBG) } \\ \rightarrow S_{21}(\text { with EBG } 2 \times 2) & \rightarrow S_{21}(\text { with EBG } 3 \times 2 \text { ) }\end{array}$

(b)

FIGURE 27: (a) Microstrip antenna array with SRS-EBG structure and (b) simulated S-parameters of array with and without proposed EBG structure.

Farahani et al. [78] proposed another multilayer configuration, where the UC-EBG is placed on the top as superstrate and the circular patch antenna array is sandwiched in between the two materials $\left(\varepsilon_{r}=10.2\right.$ and $h_{1}=h_{2}=$ $1.27 \mathrm{~mm}$ ). The antennas are fed by top loaded pin as shown in Figure 26, and the resonant frequency is selected to be $5.75 \mathrm{GHz}$. With patch separation of $0.5 \lambda_{0}, 10 \mathrm{~dB}$ reduction of coupling is observed, whereas the reduction is $13 \mathrm{~dB}$ at $0.63 \lambda_{0}$ separation. Most recently, a $4 \times 3$ array of similar UC-EBG structure with $12 \times 12 \mathrm{~mm}^{2}$ unit cell is investigated in [39] to reduce mutual coupling at 5.6 and $13 \mathrm{GHz}$. Computational investigations are performed, and the cell parameters are optimized for different frequencies. With patch separation of $0.5 \lambda_{0}$ at $5.6 \mathrm{GHz}$, the coupling is reduced by $8.5 \mathrm{~dB}$.

Alam et al. [38] also investigated their proposed SRSEBG structure for reducing mutual coupling of an E-plane coupled array as shown in Figure 27(a). Two identical coplanar microstrip patch antennas with a resonant frequency of $13 \mathrm{GHz}$ are placed $0.8 \lambda_{0}$ apart, where $\lambda_{0}$ is the free space wavelength. Each of the coaxial probe-fed patches has an area of $6.84 \times 5.56 \mathrm{~mm}^{2}$ with an overall board size of $1.8 \lambda_{0} \times 2.5 \lambda_{0}$. The microstrip antennas are placed over the same dielectric material $(1.6 \mathrm{~mm}$ thick FR4 with relative permittivity $=4.6$ and loss tangent $=0.02)$ that is used to design the SRS-EBG. Figure 27(b) shows a comparison of the mutual coupling between the microstrip antennas with and without inclusion of an SRS-EBG. The antenna without an EBG shows a strong coupling level $\left(S_{21}\right)$ of $-19.06 \mathrm{~dB}$ between the patches, and the return loss level $\left(S_{11}\right)$ is $-19.41 \mathrm{~dB}$ at the resonant frequency of $13.1 \mathrm{GHz}$. The radiating patches are strongly coupled in the E-plane due to the pronounced surface waves inside the substrate. It is clear in the figure that insertion of the SRSEBG reduces the coupling level compared to the normal case.
Because the operating band of the antennas falls inside the band gap of the proposed SRS-EBG, the surface waves are well suppressed. The coupling level drops to $-36.2 \mathrm{~dB}$ with a $2 \times 2$ $\mathrm{EBG}$ and $-39.13 \mathrm{~dB}$ with a $3 \times 2 \mathrm{EBG}$.

\section{Conclusion}

In this paper, a comprehensive survey is presented on the electromagnetic band gap structure, their various configurations, and successive improvement up to today's uni-planar design. For the RF and microwave researchers, the EBG terminology is a hot research direction to solve out many problems that degrade the functional efficiency of a system. An antenna is an indispensable part of a communication system to receive and transmit electromagnetic energy. Being completely planar, microstrip antennas are very attractive and widely used for applications starting from $\mathrm{MHz}$ to $\mathrm{GHz}$ frequency range. The low gain, narrow bandwidth, and poor radiation performance has limited their applications for many purposes. Another limitation is the pronounced surface waves inside the dielectric material, which worsen their radiation characteristics and increase the mutual coupling between elements of an array. Utilization of the EBG structures in antenna design is introduced as a revolutionary development with their versatility and aptness. Among the various designs, the uniplanar type EBG configurations are very attractive, easier to fabricate, and suitable for integration with a wide range of planar devices. However, compactness is an issue in designing EBG structures at desired frequencies, since the periodicity should be a half-wavelength at the center frequency. A few EBG structures are found of having band gaps at lower frequencies but those designs were not investigated with other microwave devices. As seen in the illustrated 
antenna-EBG combinations, attempts have been taken in diverse ways to improve antenna element performances and to reduce the mutual coupling of microstrip antenna array. This literature study will hopefully set a basis about the current state-of-the-art of EBG research and will be helpful for microstrip antenna designs.

\section{Acknowledgments}

The authors would like to express their sincere gratefulness to the Institute of Space Science (ANGKASA), UKM, and Ministry of Science, Technology and Innovation (MOSTI), Malaysia, for their support in performing this study.

\section{References}

[1] M. R. I. Faruque, M. T. Islam, and N. Misran, "Design analysis of new metamaterial for EM absorption reduction," Progress in Electromagnetics Research, vol. 124, pp. 119-135, 2012.

[2] D. M. N. Elsheakh, H. A. Elsadek, and E. A. Abdullah, Antenna Designs with Electromagnetic Band Gap Structures, Metamaterial, edited by X. Y. Jiang, InTech, Rijeka, Croatia, 2012, http://www.intechopen.com/books/metamaterial/design -antenna-with-electromagnetic-band-gap-structures.

[3] M. R. I. Faruque, M. T. Islam, and N. Misran, "Evaluation of em absorption in human head with metamaterial attachment," Applied Computational Electromagnetics Society Journal, vol. 25, no. 12, pp. 1097-1107, 2010.

[4] F. Yang and Y. Rahmat-Samii, Electromagnetic Band Gap Structures in Antenna Engineering, Cambridge University Press, Cambridge, UK, 2009.

[5] R. W. Ziolkowski and N. Engheta, "Introduction, history and selected topics in fundamental theories of metamaterials," in Metamaterials: Physics and Engineering Explorations, N. Engheta and R. Ziolkowski, Eds., chapter 1, John Wiley \& Sons, New York, NY, USA, 2006.

[6] C. Caloz and T. Itoh, Electromagnetic Metamaterials: Transmission Line Theory and Microwave Applications, John Wiley \& Sons, Toronto, Canada, 2006.

[7] D. R. Smith, W. J. Padilla, D. C. Vier, S. C. Nemat-Nasser, and S. Schultz, "Composite medium with simultaneously negative permeability and permittivity," Physical Review Letters, vol. 84, no. 18, pp. 4184-4187, 2000.

[8] S. F. Mahmoud, "A new miniaturized annular ring patch resonator partially loaded by a metamaterial ring with negative permeability and permittivity," IEEE Antennas and Wireless Propagation Letters, vol. 3, no. 1, pp. 19-22, 2004.

[9] K. Buell, H. Mosallaei, and K. Sarabandi, "Electromagnetic MetaMaterial insulator to eliminate substrate surface waves," in Proceedings of the IEEE Antennas and Propagation Society International Symposium, vol. 2, pp. 574-577, July 2005.

[10] F. Yang and Y. Rahmat-Samii, "Applications of electromagnetic band-gap (EBG) structures in microwave antenna designs," in Proceedings of the $3 r$ International Conference on Microwave and Millimeter Wave Technology, pp. 528-531, 2002.

[11] E. Yablonovitch, "Inhibited spontaneous emission in solid-state physics and electronics," Physical Review Letters, vol. 58, no. 20, pp. 2059-2062, 1987.

[12] A. Alù, M. G. Silveirinha, A. Salandrino, and N. Engheta, "Epsilon-near-zero metamaterials and electromagnetic sources: tailoring the radiation phase pattern," Physical Review B, vol. 75, no. 15, Article ID 155410, 13 pages, 2007.

[13] M. S. Alam, M. T. Islam, and N. Misran, "Inverse triangular shape CPW-fed antenna loaded with EBG reflector," Electronics Letters, vol. 49, no. 2, pp. 86-88, 2013.

[14] B. A. Munk, Frequency Selective Surfaces: Theory and Design, John Wiley \& Sons, New York, NY, USA, 2000.

[15] J. D. Joannopoulos, R. D. Meade, and J. N. Winn, Photonic Crystals, Princeton University Press, Princeton, NJ, USA, 1995.

[16] P. de Maagt, R. Gonzalo, Y. C. Vardaxoglou, and J. M. Baracco, "Electromagnetic bandgap antennas and components for microwave and (sub)millimeter wave applications," IEEE Transactions on Antennas and Propagation, vol. 51, no. 10 I, pp. 2667-2677, 2003.

[17] M. S. Alam, M. T. Islam, and N. Misran, "Design analysis of an electromagnetic bandgap microstrip antenna," The American Journal of Applied Sciences, vol. 8, no. 12, pp. 1374-1377, 2011.

[18] D. Sievenpiper, "Review of theory, fabrication, and applications of high impedance ground planes," in Metamaterials: Physics and Engineering Explorations, N. Engheta and R. Ziolkowski, Eds., chapter 11, John Wiley \& Sons, New York, NY, USA, 2006.

[19] G. H. Li, X. H. Jiang, and X. M. Zhong, "A novel defected ground structure and its application to a lowpass filter," Microwave and Optical Technology Letters, vol. 48, no. 9, pp. 1760-1763, 2006.

[20] C. S. Kim, J. S. Lim, S. Nam, K. Y. Kang, and D. Ahn, "Equivalent circuit modelling of spiral defected ground structure for microstrip line," Electronics Letters, vol. 38, no. 19, pp. 1109-1110, 2002.

[21] M. T. Islam and M. S. Alam, "Design of high impedance electromagnetic surfaces for mutual coupling reduction in patch antenna array," in Materials, vol. 6, pp. 143-155, 2013.

[22] M. R. I. Faruque, M. T. Islam, and N. Misran, "Evaluation of specific absorption rate (SAR) reduction for PIFA antenna using metamaterials," Frequenz, vol. 64, no. 7-8, pp. 144-149, 2010.

[23] M. R. I. Faruque, M. T. Islam, and N. Misran, "Study of specific absorption rate (SAR) in the human head by metamaterial attachment," IEICE Electronics Express, vol. 7, no. 4, pp. 240246, 2010.

[24] M. T. Islam, M. R. I. Faruque, and N. Misran, "SAR reduction in a muscle cube with metamaterial attachment," Applied Physics A, vol. 103, no. 2, pp. 367-372, 2011.

[25] T. Lopetegi, M. A. G. Laso, R. Gonzalo et al., "Electromagnetic crystals in microstrip technology," Optical and Quantum Electronics, vol. 34, no. 1-3, pp. 279-295, 2002.

[26] F. R. Yang, K. P. Ma, M. Y. Qian, and T. Itoh, "A uniplanar compact photonic-bandgap (UC-PBG) structure and its applications for microwave circuits," IEEE Transactions on Microwave Theory and Techniques, vol. 47, no. 8, pp. 1509-1514, 1999.

[27] D. Sievenpiper, L. Zhang, R. F. J. Broas, N. G. Alexöpolous, and E. Yablonovitch, "High-impedance electromagnetic surfaces with a forbidden frequency band," IEEE Transactions on Microwave Theory and Techniques, vol. 47, no. 11, pp. 2059-2074, 1999.

[28] Y. Toyota, A. E. Engin, T. H. Kim, and M. Swaminathan, "Stopband analysis using dispersion diagram for two-dimensional electromagnetic bandgap structures in printed circuit boards," IEEE Microwave and Wireless Components Letters, vol. 16, no. 12, pp. 645-647, 2006.

[29] A. Aminian, F. Yang, and Y. Rahmat-Samii, "In-phase reflection and EM wave suppression characteristics of electromagnetic 
band gap ground planes," in Proceedings of the IEEE International Antennas and Propagation Symposium, pp. 430-433, June 2003.

[30] Y. Yao, X. Wang, and Z. Feng, "A novel dual-band Compact Electromagnetic Bandgap (EBG) structure and its application in multi-antennasl," in Proceedings of the IEEE Antennas and Propagation Society International Symposium (APS' 06), pp. 1943-1946, Albuquerque, NM, USA, July 2006.

[31] Y. Wang, J. Huang, and Z. Feng, "A novel fractal multiband EBG structure and its application in multi-antennas," in Proceedings of the IEEE Antennas and Propagation Society International Symposium, pp. 5447-5450, Honolulu, Hawaii, USA, June 2007.

[32] L. Liang, C. H. Liang, L. Chen, and X. Chen, "A novel broadband EBG using cascaded mushroom-like structure," Microwave and Optical Technology Letters, vol. 50, no. 8, pp. 2167-2170, 2008.

[33] J. Chen, Z. B. Weng, Y. C. Jiao, and F. S. Zhang, "Lowpass filter design of hilbert curve ring defected ground structure," Progress in Electromagnetics Research, vol. 70, pp. 269-280, 2007.

[34] A. S. Barlevy and Y. Rahmat-Samii, "Characterization of electromagnetic band-gaps composed of multiple periodic tripods with interconnecting vias: concept, analysis, and design," IEEE Transactions on Antennas and Propagation, vol. 49, no. 3, pp. 343-353, 2001.

[35] E. Zbay, A. Abeyta, G. Tuttle et al., "Measurement of a threedimensional photonic band gap in a crystal structure made of dielectric rods," Physical Review B, vol. 50, no. 3, pp. 1945-1948, 1994.

[36] X. Mu, W. Jiang, S. X. Gong, and F. W. Wang, "Dual-band low profile directional antenna with high impedance surface reflector," Progress in Electromagnetics Research Letters, vol. 25, pp. 67-75, 2011.

[37] M. F. Abedin and M. Ali, "Effects of a smaller unit cell planar EBG structure on the mutual coupling of a printed dipole array," IEEE Antennas and Wireless Propagation Letters, vol. 4, no. 1, pp. 274-276, 2005.

[38] M. S. Alam, M. T. Islam, and N. Misran, "A novel compact split ring slotted electromagnetic bandgap structure for microstrip patch antenna performance enhancement," Progress in Electromagnetics Research, vol. 130, pp. 389-409, 2012.

[39] S. D. Assimonis, T. V. Yioultsis, and C. S. Antonopoulos, "Computational investigation and design of planar EBG structures for coupling reduction in antenna applications," IEEE Transactions on Magnetics, vol. 48, no. 2, pp. 771-774, 2012.

[40] R. Coccioli, F. R. Yang, K. P. Ma, and T. Itoh, "Aperture-coupled patch antenna on UC-PBG substrate," IEEE Transactions on Microwave Theory and Techiques, vol. 47, no. 11, pp. 2123-2130, 1999.

[41] O. Folayan and R. J. Langley, "Wideband reduced size electromagnetic bandgap structure," Electronics Letters, vol. 41, no. 20, pp. 1099-1100, 2005.

[42] Y. Toyota, A. E. Engin, T. H. Kim, M. Swaminathan, and S. Bhattacharya, "Size reduction of electromagnetic bandgap (EBG) structures with new geometries and materials," in Proceedings of the 56th IEEE Electronic Components and Technology Conference, pp. 1784-1789, San Diego, Calif, USA, June 2006.

[43] B. Q. Lin, Q. R. Zheng, and N. C. Yuan, "A novel planar PBG structure for size reduction," IEEE Microwave and Wireless Components Letters, vol. 16, no. 5, pp. 269-271, 2006.
[44] R. B. Waterhouse and D. Novak, "A small electromagnetic bandgap structure," in Proceedings of the IEEE MTT-S International Microwave Symposium Digest, pp. 602-605, San Francisco, Calif, USA, June 2006.

[45] T. Liu, X. Y. Cao, X. Wen, and B. Q. Lin, "A novel compact EBG structures with relative wide band-gap," in Proceedings of the Asia-Pacific Microwave Conference (APMC'07), pp. 1-3, Bangkok, Thailand, December 2007.

[46] B. Q. Lin, X. Y. Ye, X. Y. Cao, and F. Li, "Uniplanar EBG structure with improved compact and wideband characteristics," Electronics Letters, vol. 44, no. 23, pp. 1362-1363, 2008.

[47] W. Wang, X. Y. Cao, W. Y. Zhou, and T. Liu, "A novel compact uni-planar electromagnetic band-gap (UC-EBG) structure," in Proceedings of the International Conference on Microwave and Millimeter Wave Technology (ICMMT' 08), pp. 1634-1636, Nanjing, China, April 2008.

[48] H. N. B. Phuong, D. N. Chien, and T. M. Tuan, "A triplebandgap uni-planar EBG structure for antenna applications," in Proceedings of the Progress in Electromagnetics Research Symposium, pp. 1739-1743, Kuala Lumpur, Malaysia, 2012.

[49] M. N. Shakib, M. T. Islam, and N. Misran, "Stacked patch antenna with folded patch feed for ultra-wideband application," IET Microwaves, Antennas and Propagation, vol. 4, no. 10, pp. 1456-1461, 2010.

[50] M. T. Islam, M. Moniruzzaman, N. Misran, and M. N. Shakib, "Curve fitting based particle swarm optimization for uwb patch Antenna," Journal of Electromagnetic Waves and Applications, vol. 23, no. 17-18, pp. 2421-2432, 2009.

[51] A. T. Mobashsher, M. T. Islam, and N. Misran, "Wideband compact antenna with partially radiating coplanar ground plane," Applied Computational Electromagnetics Society Newsletter, vol. 26, no. 1, pp. 73-81, 2011.

[52] R. Azim, M. T. Islam, and N. Misran, "Printed planar antenna for wideband applications," Journal of Infrared, Millimeter, and Terahertz Waves, vol. 31, no. 8, pp. 969-978, 2010.

[53] J. J. Tiang, M. T. Islam, and N. Misran, "Slot loaded circular microstrip antenna with meandered slits," Journal of Electromagnetic Waves and Applications, vol. 25, no. 13, pp. 1851-1862.

[54] M. T. Islam, A. T. Mobashsher, and N. Misran, "Design of microstrip patch antenna using novel U-shaped feeding strip with unequal arm," Electronics Letters, vol. 46, no. 14, pp. 968970, 2010.

[55] R. Azim, M. T. Islam, N. Misran, S. W. Cheung, and Y. Yamada, "Planar UWB antenna with multi-slotted ground plane," Microwave and Optical Technology Letters, vol. 53, no. 5, pp. 966-968, 2011.

[56] A. T. Mobashsher, M. T. Islam, and N. Misran, "A novel highgain dual-band antenna for RFID reader applications," IEEE Antennas and Wireless Propagation Letters, vol. 9, pp. 653-656, 2010.

[57] R. Azim, M. T. Islam, and N. Misran, "A planar monopole antenna for UWB applications," International Review of Electrical Engineering, vol. 5, no. 4, pp. 1848-1852, 2010.

[58] L. Leger, T. Monediere, and B. Jecko, "Enhancement of gain and radiation bandwidth for a planar 1-D EBG antenna," IEEE Microwave and Wireless Components Letters, vol. 15, no. 9, pp. 573-575, 2005.

[59] D. Qu and L. Shafai, "Wideband microstrip patch antenna with EBG substrates," in Proceedings of the IEEE Antennas and Propagation Society International Symposium, vol. 2, pp. 594597, July 2005. 
[60] S. Pioch and J. M. Laheurte, "Size reduction of microstrip antennas by means of periodic metallic patterns," Electronics Letters, vol. 39, no. 13, pp. 959-961, 2003.

[61] Y. Horii and M. Tsutsumi, "Wide band operation of a harmonically controlled EBG microstrip patch antenna," in Proceedings of the IEEE Antennas and Propagation Society International Symposium, vol. 3, pp. 768-771, San Antonio, Tex, USA, June 2002.

[62] Y. Lee, J. Yeo, and R. Mittra, "Investigation of electromagnetic bandgap (EBG) structures for antenna pattern control," in Proceedings of the IEEE International Antennas and Propagation Symposium, vol. 2, pp. 1115-1118, June 2003.

[63] F. Yang and Y. Rahmat-Samii, "Microstrip antennas integrated with electromagnetic band-gap (EBG) structures: a low mutual coupling design for array applications," IEEE Transactions on Antennas and Propagation, vol. 51, no. 10, pp. 2936-2946, 2003.

[64] K. Siakavara, "Methods to design microstrip antennas for modern applications," in Microstrip Antennas, Nasimuddin, Ed., chapter 9, InTech, Rijeka, Croatia, 2011.

[65] M. T. Islam and M. S. Alam, "Compact EBG structure for alleviating mutual coupling between patch antenna array elements," Progress in Electromagnetic Research, vol. 137, pp. 425-438, 2013.

[66] O. Folayan and R. Langley, "Compact EBG antenna," in Proceedings of the 1st European Conference on Antennas and Propagation, pp. 1-4, Nice, France, November 2006.

[67] R. Chayono, M. Haneishi, and Y. Kimura, "Broadband CPWfed circular MSA using planar electromagnetic band-gap structure," in Proceedings of the IEEE International Workshop on Antenna Technology: Small Antennas and Novel Metamaterials (iWAT’08), pp. 462-465, Chiba, Japan, March 2008.

[68] M. Mantash, A. C. Tarot, S. Collardey, and K. Mahdjoubi, "Dual-band CPW-fed G-antenna using an EBG structure," in Proceedings of the 6th Loughborough Antennas and Propagation Conference (LAPC '10), pp. 453-456, Loughborough, UK, November 2010.

[69] M. Gujral, J. L. W. Li, T. Yuan, and C. W. Qiu, "Bandwidth improvement of microstrip antenna array using dummy EBG pattern on feedline," Progress in Electromagnetics Research, vol. 127, pp. 79-92, 2012.

[70] Y. J. Sung and Y. S. Kim, "An improved design of microstrip patch antennas using photonic bandgap structure," IEEE Transactions on Antennas and Propagation, vol. 53, no. 5, pp. 17991804, 2005.

[71] H. Liu, Z. Li, X. Sun, and J. Mao, "Harmonic suppression with photonic bandgap and defected ground structure for a microstrip patch antenna," IEEE Microwave and Wireless Components Letters, vol. 15, no. 2, pp. 55-56, 2005.

[72] R. C. Hadarig, M. E. de Cos, and F. L. Heras, "Microstrip patch antenna bandwidth enhancement using AMC/EBG structures," International Journal of Antennas and Propagation, vol. 2012, Article ID 843754, 6 pages, 2012.

[73] M. E. de Cos and F. L. Heras, "Dual-band uniplanar CPW-fed monopole/EBG combination with bandwidth enhancement," IEEE Antennas and Wireless Propagation Letters, vol. 11, pp. 365368, 2012.

[74] E. Rajo-Iglesias, O. Q. Quevedo-Teruel, and L. Inclán-Sánchez, "Planar soft surfaces and their application to mutual coupling reduction," IEEE Transactions on Antennas and Propagation, vol. 57, no. 12, pp. 3852-3859, 2009.

[75] D. Guha, S. Biswas, M. Biswas, J. Y. Siddiqui, and Y. M. M. Antar, "Concentric ring-shaped defected ground structures for microstrip applications," IEEE Antennas and Wireless Propagation Letters, vol. 5, no. 1, pp. 402-405, 2006.

[76] E. Rajo-Iglesias, O. Q. Quevedo-Teruel, and L. Inclán-Sánchez, "Mutual coupling reduction in patch antenna arrays by using a planar EBG structure and a multilayer dielectric substrate," IEEE Transactions on Antennas and Propagation, vol. 56, no. 6, pp. 1648-1655, 2008.

[77] A. Yu and X. Zhang, "A novel method to improve the performance of microstrip antenna arrays using a dumbbell EBG structure," IEEE Antennas and Wireless Propagation Letters, vol. 2, pp. 170-172, 2003.

[78] H. S. Farahani, M. Veysi, M. Kamyab, and A. Tadjalli, "Mutual coupling reduction in patch antenna arrays using a UC-EBG superstrate," IEEE Antennas and Wireless Propagation Letters, vol. 9, pp. 57-59, 2010. 

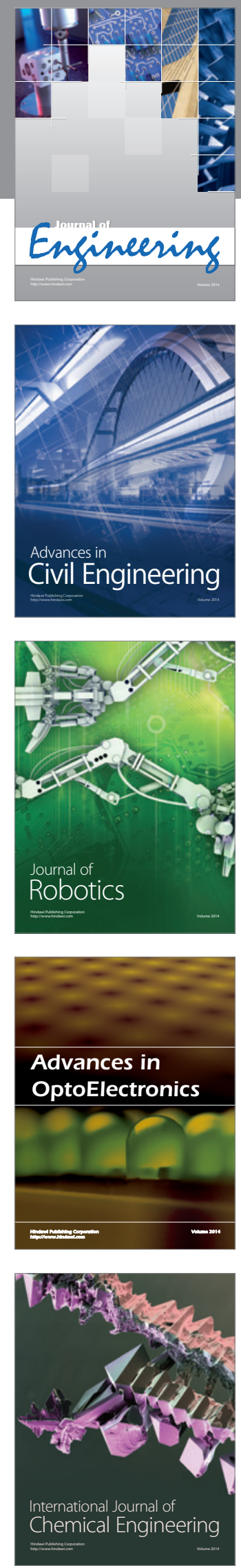

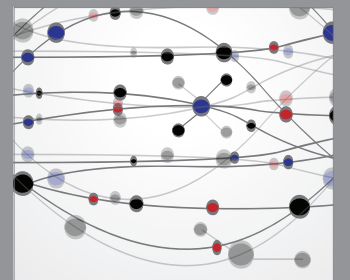

The Scientific World Journal
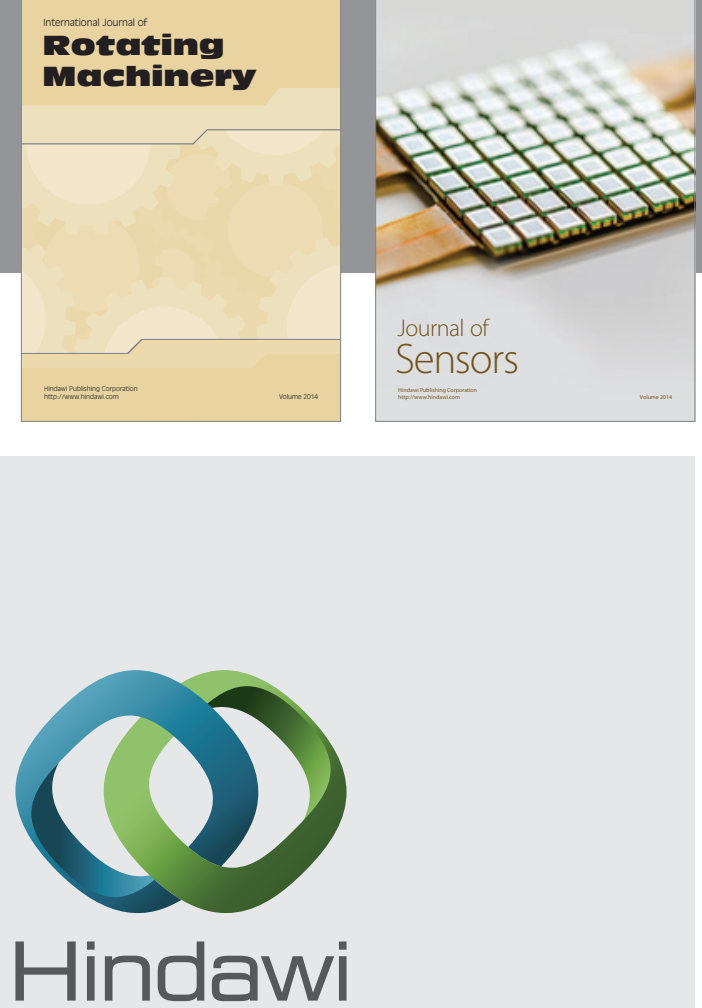

Submit your manuscripts at http://www.hindawi.com
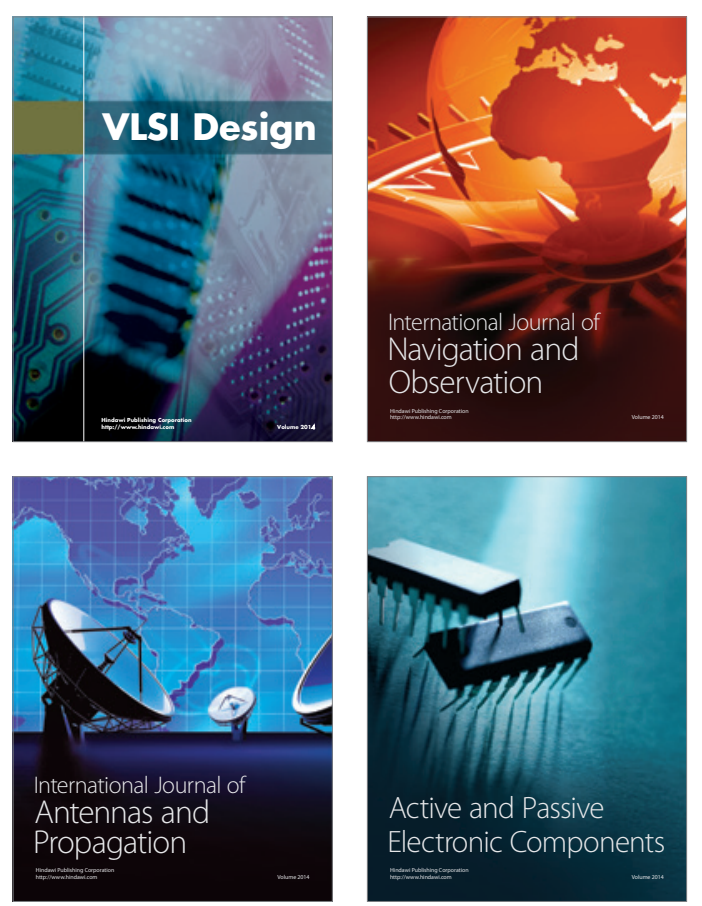
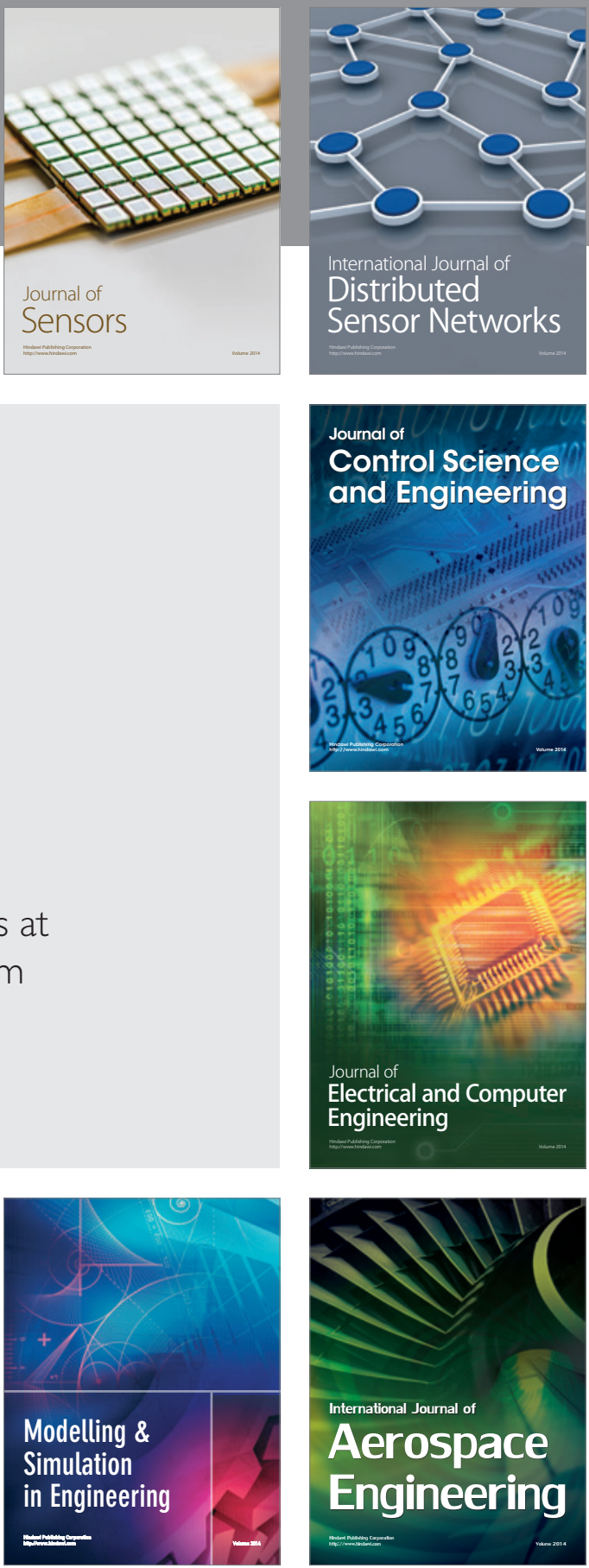

Journal of

Control Science

and Engineering
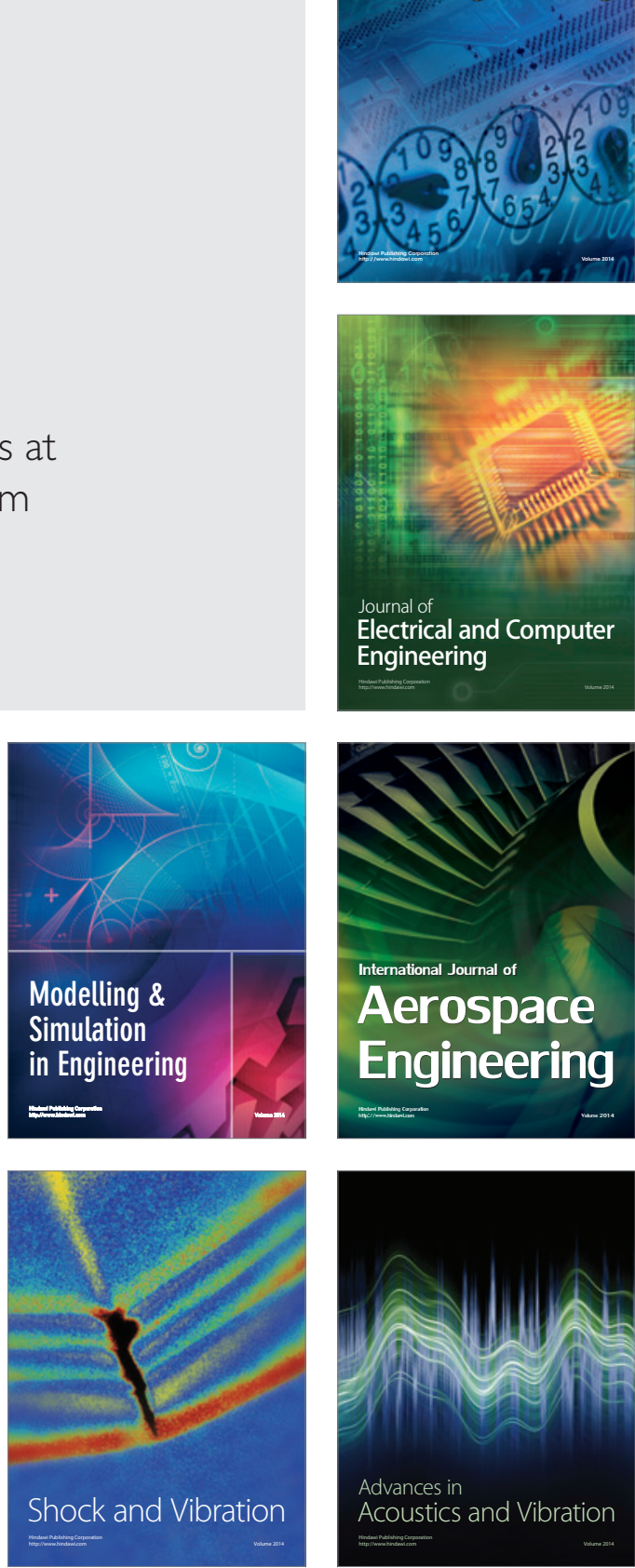